\title{
Review Article \\ Practical Guidelines: Lung Transplantation in Patients with Cystic Fibrosis
}

\author{
T. O. Hirche, ${ }^{1}$ C. Knoop, ${ }^{2}$ H. Hebestreit, ${ }^{3}$ D. Shimmin, ${ }^{4}$ \\ A. Solé, ${ }^{5}$ J. S. Elborn, ${ }^{6}$ H. Ellemunter, ${ }^{7}$ P. Aurora, ${ }^{8}$ M. Hogardt, ${ }^{9}$ \\ T. O. F. Wagner, ${ }^{10,11}$ and ECORN-CF Study Group ${ }^{11}$
}

${ }^{1}$ Department of Pulmonary Medicine, German Clinic for Diagnostics (DKD), Wiesbaden, Germany

${ }^{2}$ Department of Chest Medicine, Erasme University Hospital, Brussels, Belgium

${ }^{3}$ Department of Pediatrics, University Hospital Wuerzburg, Germany

${ }^{4}$ Regional Adult CF Centre, Belfast City Hospital, Belfast, UK

${ }^{5}$ Lung Transplant Unit, Hospital Universitario La Fe, Valencia, Spain

${ }^{6}$ Centre for Infection and Immunity, Queens University, Belfast and Adult CF Centre BHSCT, UK

${ }^{7}$ Cystic Fibrosis Center, Department of Pediatrics, Medical University Innsbruck, Innsbruck, Austria

${ }^{8}$ Paediatric Respiratory Medicine and Lung Transplantation, Great Ormond Street Hospital, London, UK

${ }^{9}$ Institute for Medical Microbiology and Infection Control, Goethe University Hospital Frankfurt, Germany

${ }^{10}$ Department of Pneumology, Goethe University Hospital Frankfurt, Germany

${ }^{11}$ Department of Pneumology, Frankfurt University Hospital, Building 15B, Theodor-Stern-Kai 7, 60590 Frankfurt, Germany

Correspondence should be addressed to T. O. F. Wagner; t.wagner@em.uni-frankfurt.de

Received 10 October 2013; Revised 8 January 2014; Accepted 9 January 2014; Published 30 March 2014

Academic Editor: Charlie Strange

Copyright $\odot 2014$ T. O. Hirche et al. This is an open access article distributed under the Creative Commons Attribution License, which permits unrestricted use, distribution, and reproduction in any medium, provided the original work is properly cited.

\begin{abstract}
There are no European recommendations on issues specifically related to lung transplantation (LTX) in cystic fibrosis (CF). The main goal of this paper is to provide CF care team members with clinically relevant CF-specific information on all aspects of LTX, highlighting areas of consensus and controversy throughout Europe. Bilateral lung transplantation has been shown to be an important therapeutic option for end-stage CF pulmonary disease. Transplant function and patient survival after transplantation are better than in most other indications for this procedure. Attention though has to be paid to pretransplant morbidity, time for referral, evaluation, indication, and contraindication in children and in adults. This review makes extensive use of specific evidence in the field of lung transplantation in CF patients and addresses all issues of practical importance. The requirements of pre-, peri-, and postoperative management are discussed in detail including bridging to transplant and postoperative complications, immune suppression, chronic allograft dysfunction, infection, and malignancies being the most important. Among the contributors to this guiding information are 19 members of the ECORN-CF project and other experts. The document is endorsed by the European Cystic Fibrosis Society and sponsored by the Christiane Herzog Foundation.
\end{abstract}

This paper is dedicated to Gerd Döring, who was a great researcher and scientist. He was also an enthusiastic participant of the CF Winter School in Obergurgl/Austria, where the ground for this paper was laid in 2012

\section{Introduction}

All aspects of CF care have been optimised over recent decades and survival continues to progressively improve; end-stage respiratory insufficiency at an adult age remains the cause of death in the vast majority of CF patients. CF constitutes the third major indication for lung transplantation (LTX) after emphysema and pulmonary fibrosis. LTX has the potential to significantly extend survival and improve quality of life (QoL) provided that candidates are referred on time 
to the transplant centre and carefully selected. Since CF is a multiorgan disease, various particularities and CF-specific complications must be taken into consideration before and after LTX, which requires a close cooperation between CF paediatricians/pulmonologists and the transplant team.

This paper was initiated in March 2012 in Obergurgl/Austria during a workshop on LTX in CF. A first draft in German was compiled based on the experts' workshop presentations and was subsequently translated into English. This English version was presented to a wider audience at an ECORN-CF (ECORN-CF: European Centres of Reference Networks for Cystic Fibrosis (ecorn-cf.eu)) meeting during the ECFS conference in Dublin/Ireland in June 2012 and working groups were established to subsequently develop the various subsections. This revision was done according to a modified (simplified to two iterations) Delphi procedure among all participants. A final revision meeting took place in April 2013 in Frankfurt/Germany.

The paper was compiled to present the latest developments in science and technology in the field of LTX for CF with particular emphasis on candidate selection, surgical preparation, and long-term care. It is intended to serve CF care team members as a guide and assist them in counselling CF patients and their families on all aspects of LTX. Since this paper was prepared by a European working group, some information given is more Europe specific and might not apply to other areas.

Questions on issues that are not included in this paper due to a lack of scientific references may be asked online at http://www.ecorn-cf.eu/.

\section{Epidemiology of LTX for CF}

Approximately 3700 lung transplantations are recorded worldwide per year by the International Society for Heart and Lung Transplantation (ISHLT) [1]. Since ISHLT registry is voluntary, the actual number of transplantations is assumed to be higher. Detailed data on waiting lists, number of transplantations, and mortality are available (http://www.ishlt.org/).

The main indications for bilateral LTX are at present emphysema (27\%), CF (26\%), and idiopathic pulmonary fibrosis (17\%). For various reasons the relative proportion of CF LTX recipients is higher in Europe as compared to the United States (US) [1].

In the cohort of all LTX recipients transplanted worldwide from 1994 to 2010, the median actuarial survival after LTX was 6.7 years; for patients, who had survived the first year, the median actuarial survival increased to 9.4 years. For CF LTX recipients these median actuarial survival times were 7.5 and 10.4 years, respectively [1].

\section{Preparation for LTX}

Please note that the preparation procedures vary from country to country.

3.1. Formal Referral to the Transplant Centre. Given the shortage of organs, the resulting waiting times, and the unpredictable evolution of end-stage CF, CF patients eligible for LTX should be referred to a transplant centre at an appropriate time. An $\mathrm{FEV}_{1}<30 \%$ of predicted values and/or a rapid decline in $\mathrm{FEV}_{1}$ despite optimal conservative treatment, malnutrition, and diabetes, female gender, frequent exacerbations and/or an increasing need for intravenous antibiotherapy, recurrent, massive hemoptysis, which cannot be controlled by bronchial artery embolisation, relapsing or complicated pneumothorax, or the need for ICU admission are all indicators that a pretransplant assessment is warranted $[2,3]$. The patient's individual motivation, current QoL, and social environment need to be taken into consideration as well $[2,4,5]$.

The patient must be fully informed about the long-term medical, psychological, and social effects of the anticipated transplantation. His explicit request for LTX, documented by written consent, is a fundamental prerequisite before being listed in some countries. Children and adolescents may not be listed against their will. Guidelines pertaining to this issue have been released in some countries [6].

3.2. Determination of the Suitable Time for Listing. Presentation at the transplant centre and admission to the waiting list are two separate decision steps. Pretransplant assessment should be carried out when there are indicators of a negative evolution but does not necessarily result in immediate listing. Acceptance onto the waiting list becomes necessary when LTX is likely to prolong life and improve QoL when compared to conservative medical treatment [7, 8]. Listing should happen when estimated life expectancy is reduced, but also at a time when it is still superior to the expected waiting time [2]. Expected waiting time may vary widely according to country, blood group, and height and these parameters should be taken into account. Still, it remains very difficult to reliably assess prognosis for an individual patient. Statistical and mathematical approaches with multivariate models for survival in the CF have not been able to identify robust predictors [3]. Country specific allocation systems play a crucial role in the decision when to list.

During the waiting period, the patient should pursue an active lifestyle in order to maintain muscle and bone mass and at least stabilise his nutritional condition. Vaccinations should be completed or boosted as needed. The social support network for the perioperative and postoperative phase should be strengthened and emotional preparation for the transplantation should be accomplished with professional help. At the same time continuous reevaluation of the medical situation is essential to make sure that any deterioration of health is detected and treated early on and results in a potential adaptation of the waiting list position (see below) [4].

3.3. Allocation of Donor Lungs. Eligible patients are put on the waiting list at their local transplant centre. In most European countries, they are then notified to an organ procurement organisation which assigns available donor lungs according to predetermined criteria. The process of organ distribution is called "organ allocation." Allocation criteria may be based on geography (regional, national, and international), urgency 
(e.g., by audit process, individual decision, or objectively by a score system) or on waiting time, or a combination of several criteria.

Eurotransplant (http://www.eurotransplant.org/) is the largest organ procurement organisation in Europe, comprising Austria, Belgium, Croatia, Germany, Luxembourg, The Netherlands, Slovenia, and-from July 2013 onwardsHungary. Spain and Portugal have their own network, as do the Scandinavian countries, France, and the UK.

Historically, lung allocation, in the US and the Eurotransplant region, was mainly based on waiting time. Recently, though, in the context of a high mortality of patients waiting for LTX (mainly of patients affected by pulmonary arterial hypertension and pulmonary fibrosis), a lung allocation score (LAS) has been devised [9]. The LAS takes into account the estimated survival benefit offered by LTX by 1 year after surgery and medical urgency. Since its introduction as a tool for donor lung allocation in the US in 2005, the number of LTX for US CF patients has increased by 25\%. Of note, $70 \%$ of wait-listed CF patients were transplanted after a waiting period of 1 year decreasing the 1-year waiting-list mortality from $15 \%$ to $10 \%$ [10]. The LAS system has also been recently adopted in Germany for LTX candidates age 12 and older. In the rest of the Eurotransplant region donor lung allocation is currently still based on waiting time and/or patient status. When waiting time is used, listing should be early.

3.4. Preoperative Examinations. An extensive work-up is necessary in preparation for LTX. Table 1 shows the common prerequisites and others that may be necessary according to the individual circumstances (e.g., right heart catheterisation) $[2,4,11]$. The results of this work-up may also help improve the baseline condition prior to LTX. Examples would be an improved nutritional status, better physical fitness through physiotherapy and rehabilitation, or the treatment of a potential focus of infection (e.g., paranasal sinuses, teeth).

\subsection{Impact of Pretransplant Upper Airways Colonisation on} LTX Outcomes. Colonisation of the transplanted lung with pathogens such as Pseudomonas aeruginosa (P.a.) may damage the allograft both directly and indirectly and probably constitutes a risk factor for chronic lung allograft dysfunction (CLAD) (see below) [12]. Pathogens cross colonise between upper and lower airways in CF $[13,14]$ and strains recovered from the transplant may be genotypically identical to those colonising the upper airways and paranasal sinuses [14, 15]. It is not clear whether conservation and/or surgical methods may prevent graft recolonisation. Surgical approaches have been advocated in order to eradicate paranasal sinus infection either before or immediately after LTX. However, since the mucous membranes of the paranasal sinuses also show the CFTR gene defect, the underlying problem of defective mucociliary clearance cannot be surgically eliminated and in any case upper airway colonisation cannot be surgically eliminated either [16]. To date, there are no reports to indicate that survival rates of CF LTX recipients with and without prophylactic pre- or posttransplant sinus surgery differ [17]. Additional studies are required to evaluate the impact of
TABLE 1: Preparatory tests for LTX* .

(i) Lab tests with blood group, HLA typing, and anti-HLA antibodies

(ii) Assessment of vaccination status, booster injection if necessary

(iii) Pulmonary function tests: body plethysmography, measurement of diffusion capacity, and standardised exercise test (iv) Chest CT without contrast agent, preferably not older than 6 months

(v) Blood gas analysis at rest

(vi) Current sputum culture

(vii) ECG, echocardiography with evaluation of pulmonary artery pressure, and right ventricular function

(viii) Right heart catheter if necessary

(ix) Assessment of nutritional status

(x) Abdominal sonography (including recording signs of portal hypertension), abdominal CT if necessary

(xi) Gastroscopy and colonoscopy if necessary

(xii) ENT examination, with sinus CT scan if necessary, throat and sinus swabs if necessary

(xiii) Bone density scan

(xiv) Gynaecological/urologic screening

(xv) Psychological assessment

(xvi) Dental examination

(xvii) Presentation at ophthalmologist

(xviii) Presentation at dermatologist

(xix) Duplex sonography of the afferent arteries if necessary

(xx) Peripheral closing pressure of the ankle arteries if necessary

${ }^{*}$ Listing reflects consensus of the ECORN-CF working group. Some centres may request further investigations.

surgical and/or conservative elimination of sinus colonisation on the long-term outcome after LTX.

3.6. General Absolute and Relative Contraindications to LTX. For each eligible patient, that is, who meets the criteria for LTX, potential contraindications should be discussed on a case by case basis with the transplant team, but not per se impede referral. Contraindications may evolve or become apparent during the waiting time and so eligibility should be regularly reconsidered.

Malignant diseases during the past 2 years are considered an absolute contraindication to LTX $[2,8]$, with the exception of nonmelanoma skin tumours such as squamouscell and basal-cell carcinomas. Most transplant centres demand a disease-free interval of 5 years. Serious extrapulmonary diseases are another absolute contraindication when combined transplantations/surgical correction is impossible. These include severe chronic renal failure, severe hepatic failure, and coronary artery disease that cannot be optimised by interventional and surgical procedures or is associated with a significantly reduced left ventricular pump function. Furthermore, active infections, including active untreated tuberculosis and chronic active hepatitis $\mathrm{B}$, are absolute contraindications. Hepatitis $\mathrm{C}$ is only a contraindication when it 
is active and results in significant histological hepatic damage $[18,19]$. Many transplant centres include HIV infection in the list of absolute contraindications although successful transplantations in this setting have been carried out $[20,21]$.

Severe neuromuscular diseases as well as serious deformations of the spinal column and chest wall and advanced osteoporosis with fractures may constitute another group of absolute contraindications. However, scoliosis, a frequent finding in CF, is not a contraindication [22].

Finally, previously documented failure to adhere to medical therapies or to follow-up, untreatable mental illness, and acute or recent addictions (over the past 6 months) such as considerable tobacco, alcohol, and substance abuse (Table 2(a)) are absolute contraindications as well.

Malnutrition results in shorter survival after LTX in general [23], but there is no evidence that nutritional status does influence posttransplantation survival in CF patients $[3,24]$.

Systemic steroid therapy should be tapered to $<20 \mathrm{mg}$ prednisolone equivalent per day before transplantation. Pretransplant endotracheal intubation and mechanical ventilation can no longer be considered as contraindication, since transplantation in mechanically ventilated patients with CF is not associated with an increase in morbidity or mortality [25, 26]. In fact, invasive mechanical ventilation or extracorporeal membrane oxygenation (ECMO) is more and more often used as a bridge to LTX. Hemodynamic instability is at least a relative contraindication. Other illnesses such as diabetes mellitus, arterial hypertension, gastroesophageal reflux disease (GERD), and osteoporosis [24] will need optimal management prior to transplantation. A significantly reduced functional status without potential for rehabilitation is also regarded as a relative contraindication.

Colonisation with multi- or panresistant P.a. in CF patients does not result in inferior outcomes [27, 28]. Colonisation with MRSA, multi- or panresistant Gram-negative rods such as Stenotrophomonas maltophilia or Achromobacter species (xylosoxidans) is also no reason to deny LTX [28]. In contrast, Burkholderia cepacia complex (Bcc) infection in CF patients may be associated with septic clinical courses including the so-called "cepacia syndrome" when $B$. cenocepacia, B. multivorans, and B. dolosa are involved. The literature reports higher mortality rates after LTX for CF patients colonised with Bcc, especially for those colonised with $B$. cenocepacia and in some reports for those colonised with B. multivorans [29-32]. Dismal outcomes have also been reported in patients colonised with a Gram-negative bacteria closely related to Bcc, Burkholderia gladioli [29-33]. Many LTX centres therefore decline patients presenting with these pathogens (Table 2(b)). However, a case by case evaluation is mandatory [34].

Nontuberculous mycobacteria (NTM) also pose significant challenges after LTX (see below). The prevalence of NTM in CF patients ranges from 3 to 19\% [35]. M. avium complex (belonging to slowly growing mycobacteria) is most common in the US, whereas $M$. abscessus complex (belonging to rapidly growing mycobacteria) prevails in Europe. Detection of NTM is currently not rated as an absolute contraindication to LTX. Centers that accept patients with
TABLE 2: Contraindications to LTX.

(a) Absolute contraindications to LTX

(i) Malignant diseases in the past 2 years

(ii) Untreatable severe dysfunction of another important organ system (heart, liver, and kidney) not amenable to surgical correction/combined TX

(iii) Chronic, incurable extrapulmonary infection

(iv) Severe deformations of chest and spine

(v) Severe or symptomatic osteoporosis

(vi) Lack of adherence to therapy

(vii) Untreatable mental disorders combined with lack of cooperation

(viii) Addictive disorder currently or during the past 6 months (tobacco and alcohol addiction, substance abuse)

(b) Relative contraindications to LTX

(i) Age $>65$ years

(ii) Critical/unstable clinical situation

(iii) Seriously limited functional status without potential for rehabilitation

(iv) Colonisation with Burkholderia cenocepacia, Burkholderia gladioli and Mycobacteria abscessus

(v) Diseases not optimally treated (e.g., arterial hypertension, diabetes mellitus, GERD, osteoporosis, and coronary heart disease)

M. abscessus infection for transplantation usually advocate aggressive treatment prior to and after LTX [36].

3.7. Preoperative Nutritional Management. Lung function and nutrition are codependent variables in CF. Moreover, the nutritional status has a considerable impact on muscular function. Poor nutritional status is an independent risk factor for poor survival in CF [37-39].

Extremes of body weight, body mass index (BMI) and lean body mass (LBM) have been shown to negatively affect LTX outcome [24, 40-43]. A healthy weight should be promoted long before LTX is indicated [40]. This being said, CF patients with end-stage lung disease are at risk of significant weight loss as energy expenditure is increased on one hand (secondary to the increased work of breathing and the chronic bronchopulmonary infection) and optimal calorie uptake is compromised on the other hand (by the exocrine pancreatic insufficiency, a loss of appetite in the context of inflammation/infection, and the respiratory discomfort caused by gastric distension after meals) [44-46]. Relevant nutritional information should be exchanged between dietitians from the referring CF centre and the transplant centre to optimise management. Wait listing should not be unduly delayed while attempts are made to correct a low BMI, as this might result in a higher wait list mortality [9].

\subsection{Psychosocial Evaluation and Support}

3.8.1. Psychosocial Evaluation. The psychosocial functional level of adolescent CF patients is compared to that of a 
normal random sample-until the disease is taking a more serious course [47]. In adult CF patients the prevalence of anxiety is higher whereas the prevalence of depression is lower when compared to the general population [48]. The emotional strain is even higher for relatives, with a third to half of the people interviewed being affected. The pretransplantation anxiety scores are nevertheless lower in CF patients, as they have better social support and more functional coping strategies, than in patients, who need LTX for other indications $[49,50]$.

Data on the significance of mental illnesses and on psychosocial indicators regarding the outcome of LTX are contradictory. Some authors suggest that mental illness is a relative or absolute contraindication [51], others emphasise that these disorders are relatively well treatable [52] or request suitable support services at transplantation centres [53]. Evaluation of LTX candidates by an external psychiatrist is unnecessary; instead it has been advocated to involve a psychologist, a psychiatrist, a psychosomatically experienced physician, and/or a social worker in the care-giving team [54]. If the CF and TX centre have different locations and teams, it is important to develop a good communication between them in order to enable the patient's psychosocial evaluation, support, and integration in the new team.

There are several instruments to measure adherence and psychosocial adjustment. An example would be the compact Transplant Evaluation Rating Scale (TERS) [55], which allows for a structured psychosocial evaluation and enables the examiner to assess the patient with regard to the following domains: substance abuse, compliance, health consciousness, social support, past coping, dealing with the current disease, affect and mental status.

Sex and age have an additional bearing on treatment adherence. Young female CF patients encounter significantly more emotional tension and concern about their disease, their degree of self-esteem is lower, they tend to be more readily disappointed about treatment, and their adherence in certain areas of treatment is inferior [56]. CF adolescents feel and behave differently from CF adults. The tasks of developing autonomy and shaping identity are radically changed when the indication of an organ transplantation is given [54]. The relationship with the doctor and the CF team is considered an important factor to promote adherence in CF patients [57].

3.8.2. Psychosocial Counselling, Therapeutic Education, and Support Groups. Different forms of psychosocial support intend to enhance adherence, health-related QoL, the individual coping with illness-related anxiety, and the transplantation experience. While therapeutic education promotes active, cognitive, knowledge-based coping styles, psychosocial counselling and support groups focus more on emotional adaptation and integrating processes. Dealing with regression, the transplantation experience, or a postoperative delirium, it is also important to consider the patient's defence mechanisms and use it during post-TX counselling. The patient's mental representation of the donor and the integration of the transplanted organ are seen as a positive assimilation strategy or a disintegrative process [58].
Central topics in the counselling of CF patients prior to LTX include patient education, enhancement of selfefficiency, coping, and the definition of treatment objectives and purposes in life [54]. In the postoperative period, the desired extent of psychosocial counselling and support remains nearly as high as pre-TX. The prevalence of anxiety disorders is unchanged whereas depression decreases [53]. Rejection, side effects of medication, return to "normalcy," feelings of guilt [59], and social and legal questions are among the primary issues for which psychosocial support and counselling are sought. Adolescent CF LTX recipients are also dealing with long-term goals (e.g., $80 \%$ wish to get married and have children), interpersonal relations (peers, feeling of belonging), and the desire to regain control over their everyday life and their illness. Psychological help and support for LTX patients have proved successful and have been firmly established in a number of transplant centres [60]. In addition, self-help organisations are increasingly taking over important tasks of counselling and support.

\section{Perioperative Approach}

4.1. Bridge to Transplant. At the preterminal stage of respiratory failure, extended intensive care measures may become necessary to stabilise the patient in imminently lifethreatening situations. In the event of terminal failure of gas exchange, various temporary organ replacement options are available as "lung replacement" after conventional ventilation modalities have been exhausted. These extracorporeal life support systems (ECLS) enable direct oxygenation of or $\mathrm{CO}_{2}$ extraction from the blood. When LTX is indicated, these technologies (in particular interventional lung assist (iLA), venovenous or venoarterial extracorporeal membrane oxygenation ( $V V$-/VA-ECMO)) may be used as a bridge to transplant. Experienced centres report 1-year survivals of 60-92\% [61-63]. These bridging modalities are resourceintensive; they may be maintained for a limited time (a maximum of some/several weeks). Prompt organ availability is a prerequisite for a successful outcome in these situations.

4.2. Surgical Procedures. The surgical techniques for LTX are nowadays similar throughout the world. Therefore, we will not discuss well-known surgical details but will focus on special considerations in CF patients.

4.2.1. Lung Donation and Allocation. While the vast majority of donor lungs are retrieved from donors after brain death (DBD), donation after circulatory death (DCD) has led to a substantial increase in available donor organs over the last years $[64,65]$. Lungs from DCD donors have been successfully transplanted in CF patients. Furthermore, ex vivo lung perfusion technique (EVLP) is an emergent new option to increase the donor pool. It allows to evaluate otherwise unacceptable donor lungs over several hours after retrieval and to recondition them for subsequent LTX [66-68].

Donor lung allocation is principally based on blood group compatibility and size matching. Size matching is primarily based on donor and recipient predicted total lung capacity (TLC). It has to be taken into account that in CF recipients 
sometimes the real TLC can differ significantly from the predicted TLC [69]. At present, there is no matching for major histocompatibility antigens nor for viral (CMV, EBV) status of donor and recipient.

4.2.2. Type of Lung Replacement. Given that a remaining CF lung would serve as a source of infection, CF patients generally require a bilateral LTX. The most widespread operative technique today is bilateral sequential LTX [70]. The most widespread operative technique today is bilateral sequential LTX [70]. In rare circumstances, where there is a retracted and destroyed lung in one of the thoracic cavities and a hyperdistended lung on the other side accompanied by a fixed shift of the mediastinum, a single-lung transplant combined with a pneumonectomy of the destroyed lung or combined heart-lung transplantation can be indicated.

4.2.3. Operative Technique. The most common approach for $\mathrm{CF}$ recipients is a bilateral anterolateral thoracotomy that provides the best exposure to both lungs and the heart. Transverse sternotomy is only performed if exposure warrants it. Positioning of the patient is supine with abducted arms and the chest elevated by inflatable cushions.

During pneumonectomy, in case of a previous pleurodesis or dense pleural adhesions, special attention has to be paid to avoid phrenic and left recurrent laryngeal nerve injury while mobilizing the lungs (see below). Pneumonectomy is started with stapling of the pulmonary vessels. The bronchus is prepared centrally and cut with a scalpel, and the lung is removed from the chest cavity. Denudation of the recipient bronchus beyond the level of the planned anastomosis should be avoided by any means to prevent ischemia of the bronchial anastomosis (see below); however, bulky or calcified nodes at the recipient hilum can sometimes be a challenge during dissection. Any excessive lymphadenectomy should usually be avoided to prevent significant mediastinal bleeding, though it may sometimes be indicated to reduce infection load in recipients infected with NTM [71].

Prior to the implantation of the donor lung, it is crucial to achieve accurate hemostasis, since parts of the chest cavity are difficult to access once the lung has been implanted. In particular the posterior mediastinum can be a source of significant bleeding in CF recipients.

Donor lung preparation is usually performed immediately prior to implantation. The bronchus is shortened with only one cartilage ring remaining after the separation of the upper lobe bronchus. The peribronchial tissue has to be preserved and denudation of the bronchus has to be avoided under all circumstances to prevent bronchial healing complications (see below) [72].

4.2.4. Size-Reduced LTX. Given that many CF recipients are still smaller than the average population, the waiting time until an appropriate donor lung can be identified may become unacceptably long. Therefore, several techniques have been developed to accept oversized donor organs for urgent paediatric or small adult recipients [73]. Available data show no adverse effect of pneumoreduction on survival and posttransplant spirometry, allowing safe use of larger donors in small CF recipients [74, 75].

In case of a moderate size mismatch, nonanatomical segmental resections are a straightforward technique to reduce the size of the donor lung. The middle lobe and the lingula are the preferred target areas for these resections, which are performed immediately prior to the implantation or after the lungs are implanted and perfused.

In case of a more significant size discrepancy, lobar transplantation is another option. Some specialised centres perform living-related transplantation of (usually the lower) lung lobes from two healthy relatives/donors. Living-related lobar transplantations are exceptional procedures [76]. Split lung transplantation is performed by subdividing the parenchyma of a left donor lung and replacing the right recipient lung by the donor's upper lobe with inverse anastomosis of the bronchus (pars cartilaginea to pars membranacea). The recipient's left lung is replaced by the donor's lower lobe [73].

4.2.5. Extracorporeal Support. The routine use of intraoperative ECLS in bilateral LTX is still controversial. For many CF patients, extracorporeal support becomes necessary during surgery, though. This is often due to insufficient oxygenation on single-lung ventilation or hemodynamic instability, partly because of the necessity of retracting the heart to facilitate the exposure in the rather small chest cavities of these patients, but especially in patients with secondary pulmonary arterial hypertension. ECLS facilitates intraoperative cardiocirculatory and respiratory stability. They also protect the first implanted lung, which is otherwise exposed to the entire cardiac output during the transplantation of the second lung, from the consequences of uncontrolled reperfusion, which might result in reperfusion oedema and primary graft dysfunction (PGD) [62].

The most widespread intraoperative support device is cardiopulmonary bypass (CPB). However, an increasing number of institutions use venoarterial ECMO with heparin-coated cannulas instead of $\mathrm{CPB}$, which avoids full heparinisation and therefore leads to reduced blood loss. This approach can be especially recommended for CF patients, who very often present with dense pleural adhesions and a resulting high risk of pleural bleeding. Intraoperative extracorporeal support can be provided either by central or peripheral cannulation over the femoral vessels [77].

4.3. Surgical Complications. The surgical complications occurring in LTX may be evident peri- and postoperatively up to several months after surgery. Early complications include hemorrhage, reperfusion injury, vascular obstructions, nerve lesions, and wound infections. Later complications are mostly bronchial suture healing defects.

4.3.1. Bleeding. Hemorrhages after LTX are the most common complication. CF recipients in particular tend to develop more serious bleedings in the peri- and postoperative period due to pleural adhesions. If chest surgeries or pleurodeses were performed prior to LTX, the surgical risk is greatly increased [78]. It is not unusual that patients-after a successful LTX-have to return to the operating room in 
the immediate postoperative period for clot removal and cleansing of the pleural spaces.

4.3.2. Reperfusion Injury. Reperfusion of the donor lung may lead to reperfusion injury and reperfusion edema, which may result in PGD. Clinically, PGD occurs during the first 24 to 72 hours after LTX and mimics classical acute respiratory distress syndrome (ARDS). The severity of PGD is classified following ISHLT criteria [79]. Treatment is similar to ARDS. Histology usually confirms diffuse alveolar damage. Mortality correlates with the severity of PGD and is one of the main causes of death in the early postoperative period of LTX [80]. Furthermore, PGD is also a hazard for bronchiolitis obliterans syndrome and chronic graft rejection [81].

4.3.3. Vascular Complications. Surgical vascular complications may occur at the suture sites with secondary obstruction or thrombosis of the vessel. Severe and life-threatening consequences of angio-occlusions culminate in total graft failure or in a fulminant infarction. Immediate surgical repair should always be the therapeutic intervention, that is, complete thrombectomy $[82,83]$. After LTX, there is also an additional increased risk of deep vein thrombosis and pulmonary artery embolism [84].

4.3.4. Nerve Lesions. Phrenic nerve palsy is an infrequent, but potentially serious complication of LTX. Phrenic nerve injury may result from traction during lung mobilisation, traumatic dissection, thermal injury by electrocautery, or local topical hypothermia. If bilateral, phrenic nerve palsy may require prolonged ventilatory support either by mechanical ventilation via a tracheostomy or by noninvasive ventilation. It may recover over time $[85,86]$. Recurrent laryngeal nerve palsy may also occur and lead to vocal cord paralysis.

4.3.5. Airway Complications. The correct healing of the bronchial sutures is a major challenge after LTX, as the bronchial artery circulation is not reestablished and these sutures are, thus, prone to ischemia. The healing of the bronchial anastomoses is typically classified according to Whitson et al. [80]. Bronchial anastomotic complications have been significantly reduced by improved surgical techniques in recent years and in most centres the reported prevalence is $<5 \%$ by now; however, wide variations are seen as there is no standardised approach to reporting these complications [87]. Bronchial anastomotic complications include necrosis, stenosis, malacia, and dehiscence [88]. Many cases can be managed conservatively; those which require treatment can mostly be solved by interventional endoscopic procedures (e.g., high-frequency diathermia, laser therapy, cryotherapy, balloon bronchoplasty, endobronchial brachytherapy, and stent implantation) [89]. Repeated surgical measures such as resurgery of anastomosis, sleeve surgery, and retransplantation are only performed in exceptional cases.

Probably because of preservation issues some patients develop bronchial complications at sites distinct of the bronchial anastomoses, such as, for example, the vanishing bronchus intermedius syndrome [90].
4.3.6. Wound Infections. Due to induction therapy and consecutive immune suppression, wound infections after LTX are frequent complications. However, serious complications that require surgical (re)intervention are rather rare $(<1 \%)$ [91]. A high index of suspicion must be maintained as these immunosuppressed patients do not readily develop fever or full-blown symptoms. Persisting complaints of thoracic pain warrant evaluation for wound infection, pleural and/or mediastinal infection as during dissection the thoracic cavity may be contaminated.

4.4. Perioperative Nutritional Management. In the immediate postoperative period, maintenance of adequate nutritional intake is a priority. Energy and protein requirements are based on recommendations for general surgical and other types of transplant patients as currently there is no specific data for CF [92]. Oral diet can usually resume on postoperative day (POD) 1 or 2 if the patient has been extubated swiftly. Oral intake should be increased as tolerated with provision of adequate pancreatic enzyme replacement therapy (PERT) [46, 93]. Appetite generally improves as breathing becomes easier, bowel function normalises, and mobility improves. However, anorexia, changes in taste, nausea, vomiting, diarrhoea, or constipation may limit oral intake [46]. These may be due to medical conditions, but a number of the medications used to prevent or treat rejection and infection, including antibiotics and antifungal drugs, can also cause nausea, vomiting, diarrhoea, and changes in taste and affect dietary intake. This is especially observed during the early postoperative period when the patients receive very complex medication regimens. Supplementary enteral feeding should be initiated if oral intake is insufficient if the patient is unable to commence an oral diet by POD 3-4 or if longer-term (non)invasive ventilation is required. Patients, equipped with a gastrostomy tube, can usually reduce the use of enteral feed as oral intake increases and nutritional status becomes adequate. At a distance from surgery removal of the gastrostomy tube can be discussed between the patient, CF team, and LTX team and assessed on an individual basis. Ideally, the removal should only occur when a BMI $>19 \mathrm{~kg} / \mathrm{m}^{2}$ has been achieved and maintained for 3-6 months without supplementary nutrition [94].

Following LTX, routine monitoring of fat soluble vitamin levels is recommended, as supplements may have to be reduced or discontinued. Hypervitaminosis $\mathrm{A}$ and $\mathrm{E}$ have been reported $[95,96]$ even after supplementation ceased. The etiology of this is unclear but may be due to altered absorption, drug interactions, impaired retinol interactions, or increased hepatic synthesis of retinol-binding protein.

Immunosuppression increases the risk of new onset secondary diabetes, especially in the immediate postoperative period or during treatment of acute rejection (AR) with high-dose steroids. Special attention must be paid to glucose controls at these times, especially in patients with no previous history of diabetes and who may not easily recognise symptoms associated with hyperglycaemia. The immunosuppressive regimen may also decompensate already existing CF-related diabetes (CFRD) [93, 97, 98]. Insulin is 
usually required along with tailored nutritional management to optimise blood glucose control.

Gastrointestinal complications are common post-LTX. In the early postoperative period, constipation and distal intestinal obstruction syndrome (DIOS) are common, particularly among patients with a history of DIOS, previous major abdominal surgery, or meconium ileus in infancy $[99,100]$. Since DIOS is associated with severe complications such as perforation and sepsis, some centers recommend pre-op bowel preparation in all CF patients. Counselling on adequate fluid and dietary fiber intake should be provided and bowel movements should occur within the first 48-72 hours after surgery otherwise laxatives/enemas should be administered.

Clostridium difficile colonisation or recurrent infection is common in older CF patients and diarrhoea posttransplant should immediately trigger stool cultures and empirical treatment until stool culture results become available as Clostridium colitis in the setting of immunosuppression may be devastating.

The risk of osteoporosis, which is generally higher as a result of the underlying disease, is additionally increased post-LTX. Pathogenesis is multifactorial, with long-term use of corticosteroids and the calcineurin inhibitors (CNIs) (tacrolimus or cyclosporine A) as contributing factors [4]. Adequate calcium and vitamin D intake should be encouraged along with weight-bearing exercise and antibone resorptive medication as required.

\section{Postoperative Care}

5.1. Long-Term Follow-Up after LTX. After LTX problems arising from the genetic disorder continue to require $\mathrm{CF}$ specialist input, but specific posttransplant aspects have to be dealt with as well. Sometimes the CF-specific topics are predominant; at other times the posttransplant management issues are more acute. CF LTX recipients should ideally be followed in an institution where CF and LTX centre are closely cooperating and located in near vicinity in order to receive the best possible support with respect to both conditions. In most situations the transplant team will take the lead and the CF team will support this management. In real life, though, many CF patients have to travel a long way for LTX and consequently for posttransplant care are more frequently seen in their CF centres or by their general practitioners (GP). Irrespective of the model of shared care, there has to be close contact between all actors involved in post-LTX care and management. Accurate agreements about the tasks, functions of control, and coordination to be taken over by either the LTX centre or the CF centre, and/or the GP are required in the long run [101]. The patient's GP can become an important actor as he is often the first contact in case of problems and, thus, should always be informed about the patient's current status. He may also assume the task of reviewing lab tests and drug levels. However, the role of the GP in specific posttransplant care varies between countries, even in Europe.

All team members involved in post-TX CF care share the responsibility to detect signs of patient deterioration and post-TX complications as early as possible (e.g., malaise, fever, sputum production, dyspnea, decrease in lung function, diarrhoea, etc.).

As a general rule, any new respiratory symptom or sign in the immunosuppressed CF LTX recipients requires immediate attention and contact with the transplant centre. For a CF patient, who has lived with a limited lung function for years and who has had a successful LTX, this might not make immediate sense; however, after a successful LTX it is expected that the patient is free of respiratory symptoms and furthermore the immunosuppression may partially mask symptoms/signs so that even minor respiratory symptoms/signs might point to a serious problem.

New digestive problems, especially vomiting and diarrhoea, may compromise the absorption of immunosuppressive medications and, thus, expose the patient to a risk of $\mathrm{AR}$ and/or have a negative impact on renal function. As a consequence this type of symptoms should be taken seriously as well.

Certain viral infections, such as CMV, EBV, and varicella, can be life-threatening for transplanted CF patients [102].

Apart from LTX-related complications, CF LTX recipients are at risk for disease-specific complications that may have a significant impact on their long-term outcome. The risk of developing CFRD is markedly increased $[97,103,104]$.

Considerable evidence demonstrates a relationship between gastroesophageal reflux disease (GERD) and bronchiolitis obliterans syndrome (BOS) [105].

Markers of aspiration-induced injury may be studied in BAL or induced sputum. Acid neutralisation by administering proton pump inhibitors seems to be insufficient to protect against aspiration injury [106]. In contrast, surgical therapy by fundoplication is associated with decreased levels of markers of aspiration in BAL as well as a reduced incidence of BOS or improvements in lung function in patients already diagnosed with BOS [107]. CF LTX recipients have an even significantly higher prevalence (90\%) of GERD when compared to other LTX recipients suggesting that CF patients in particular should be routinely screened for GERD after transplantation to identify those who may benefit from antireflux surgery [108].

The risk of osteoporosis is further increased after LTX due to the long-term administration of corticosteroids and CNIs [4]. Close follow-up on the bacterial spectrum in the airways is indispensable as chronic infections with CFspecific pathogens can persist in the upper airways and reinfect the transplanted lung.

5.2. Immunosuppression. LTX recipients are usually on a triple immunosuppressive therapy combining a CNI (tacrolimus (tac) or cyclosporine A (CsA)), an antiproliferative agent (mycophenolate mofetil (MMF), mycophenolate sodium (MPS), or azathioprine (aza)), and glucocorticoids (Table 3). The immunosuppressive therapy is usually steered by the LTX centre, but monitoring is usually provided by the GP and the $\mathrm{CF}$ centre as well. The target levels of immunosuppressive drugs depend on the time elapsed since LTX and associated comorbidities (Table 4). An individual drug target level for each patient should be determined in short intervals and communicated to each care team member (LTX centre, GP 
TABLE 3: Typical baseline immunosuppression beyond one year after lung transplantation*.

\begin{tabular}{lc}
\hline Therapy & Dosing \\
\hline Prednisone/prednisolone & $5 \mathrm{mg}$ daily \\
\hline $\begin{array}{l}\text { Mycophenolate mofetil } \\
\text { or } \\
\text { mycophenolic acid }\end{array}$ & $500-1500 \mathrm{mg}$ twice daily \\
\hline $\begin{array}{l}\text { Cyclosporin A } \\
\text { or } \\
\text { tacrolimus }\end{array}$ & Targeting blood level of $150-200 \mathrm{ng} / \mathrm{mL}$ \\
\end{tabular}

${ }^{*}$ Please note that patient-specific dosages have to be taken into account.

TABLE 4: Cyclosporin and Tacrolimus can be monitored by trough levels.

\begin{tabular}{lcc}
\hline $\begin{array}{l}\text { Posttransplant } \\
\text { period }\end{array}$ & $\begin{array}{c}\text { Cyclosporin A } \\
(\mathrm{ng} / \mathrm{mL})^{* \#}\end{array}$ & $\begin{array}{c}\text { Tacrolimus } \\
(\mathrm{ng} / \mathrm{mL})^{* \#}\end{array}$ \\
\hline 0-2 weeks & $300-350$ & $10-15$ \\
3-8 weeks & $250-300$ & $10-15$ \\
2-3 month & $200-250$ & $10-15$ \\
3-6 month & $190-250$ & $10-15$ \\
6-12 month & $150-200$ & $5-10$ \\
>1 year & $150-200$ & $5-10$ \\
\hline
\end{tabular}

${ }^{*}$ Please note that reference values for drug levels are given as guidance only and may vary between centers. Patient-specific drug levels have to be taken into account.

${ }^{\#}$ In some centres postdose levels are monitored. Specific reference values are necessary.

and CF centre). Decisions of the LTX centre to wean patients down to a low steroid dose will be based on considerations of individual parameters including acute rejection (AR) episodes, the degree of renal dysfunction, and side effects.

5.3. Acute Rejection. The incidence of AR of the transplanted lung is high for several reasons, the most important being that there is no possibility for HLA matching. As a consequence most LTX recipients receive completely mismatched grafts [109].

Data from the ISHLT Registry indicate that approximately $35 \%$ of patients experience at least one AR episode during the first year after being discharged from the hospital $[110,111]$. Apart from the obvious immunological risk factors, any inflammatory/infectious damage to the lung allograft probably increases the risk for AR. For example, viral infections-such as community-acquired respiratory viral infection or CMV infection-have been associated with an increased risk of AR [112].

The clinical picture of AR is unspecific. The complete picture of dyspnea, fever, pleuritic pain, and effusion is only observed in the immediate postoperative period. A drop of $\mathrm{paO}_{2}$ or $\mathrm{FEV}_{1}$ may provide hints. The chest CT scan may show air trapping, septal thickening, ground glass densities, bronchial dilatation, bronchial wall thickening, and centrilobular opacities, but these findings are altogether nonspecific and, most importantly, are unable to differentiate AR from infection [113].
The gold standard for the diagnosis of AR is lung histology based on transbronchial biopsies (TBBs). TBBs are assessed for acute cellular vascular and bronchiolar rejection. The severity of these processes is graded according to the ISHLT classification [100]. The A grades define vascular rejection according to the severity of perivascular and interstitial mononuclear infiltrates (A0 to A4). The B grades stage synchronous bronchiolar rejection according to the severity of lymphocytic infiltration within the bronchiolar walls (B0 to B2R) [114]. Histological interpretation of TBBs is not always straightforward; there may be considerable interexaminer variability.

The vast majority of LTX centres will give treatment for $A R$ graded $\geq A 2$. Opinions differ regarding the indication for treatment in case of A1 rejection. Standard therapy consists of intravenous high-dose pulse steroid therapy (e.g., 500$1000 \mathrm{mg}$ methylprednisolone daily for 3 days). Other options, mainly for recurrent or persistent AR, include antithymocyte globulin (ATG), alemtuzumab (anti-CD52), extracorporeal photopheresis, and anti-IL2 receptor antagonists.

While the existence of antibody-mediated rejection (AMR) after LTX is at present acknowledged, its diagnosis carries many pitfalls. When a diagnosis of AMR can be established, specific treatments such as high-dose steroids combined to plasmapheresis and intravenous immunoglobulins and, possibly, rituximab, bortezomib, or eculizumab may be considered though not evidence based.

5.4. Chronic Lung Allograft Dysfunction (CLAD). Chronic lung allograft dysfunction (CLAD), especially bronchiolitis obliterans (BO), remains the major medium- and long-term problem in LTX and the leading cause of death.

BO is characterised clinically by progressive shortness of breath accompanied by a progressive and irreversible obstructive spirometric defect. The histological hallmark of this entity is obliteration of terminal bronchioles and evidence of aberrant remodeling in the airway epithelium, vasculature, stroma, and lymphoid system. $\mathrm{BO}$ is, initially at least, a heterogeneous process and histological diagnosis is difficult as TBBs are prone to sampling errors [115].

For this reason, a functional corollary, bronchiolitis obliterans syndrome (BOS), has been devised by the ISHLT. After LTX, the 2 best measurements of vital capacity (VC), FEV and $\mathrm{FEF}_{25-75}$ (obtained at least 3 weeks apart), are computed and averaged on a regular basis. At each consultation the patient's lung function parameters are compared to these best values. A chronic decline in lung function with an obstructive pattern and without any identifiable cause (such as AR, bronchial anastomotic complications, bronchopulmonary infections, phrenic nerve palsy, and pleural effusions) is, then, graded according to the ISHLT BOS classification. There are 5 stages: BOS 0 (no decline in lung function), BOS 0-p (potential BOS), and BOS 1-3 [116].

The clinical presentation of $\mathrm{BO} / \mathrm{BOS}$ is very heterogeneous. The type of presentation, the time from transplantation to onset, and the rate of progression are all very variable. $\mathrm{BO} / \mathrm{BOS}$ may present as an acute illness and imitate a respiratory infection, but very often it is at first an asymptomatic process revealed by an insidious decline in 
lung function. In a minority of patients $\mathrm{BO} / \mathrm{BOS}$ may develop within 2 years of LTX (early-onset BOS); however, the vast majority of affected patients develop the complication at a later time-point. The rate of decline in lung function is also very variable: in some patients the decline is very rapid, in others a slow decline over years is observed. Older reports indicate that survival 5 years after LTX is $20-40 \%$ lower in patients, who had a diagnosis of $\mathrm{BO} / \mathrm{BOS}$ compared to patients free from $\mathrm{BO} / \mathrm{BOS}$ [117]. However, these data have potentially evolved and series, which have not differentiated $\mathrm{BO} / \mathrm{BOS}$ from other conditions such as, for example, RAS (see below), probably overestimate $\mathrm{BO} / \mathrm{BOS}$ mortality rates. Of note, however, early-onset $\mathrm{BO} / \mathrm{BOS}$ (within 2 years) shows a worse prognosis than does late-onset $\mathrm{BO} / \mathrm{BOS}$.

Known risk factors for $\mathrm{BO} / \mathrm{BOS}$ are recurrent episodes of $\mathrm{AR}$, the development of anti-HLA antibodies, but also bacterial/fungal colonisation of the graft ( $P$. aeruginosa recolonisation of the lung transplant is considered an independent risk factor for the development of CLAD [118]), communityacquired respiratory viral infection, CMV pneumonitis and GERD.

Prevention of $\mathrm{BO} / \mathrm{BOS}$ includes addressing all known risk factors. This is the reason why at least 50\% of LTX programs perform surveillance TBBs during at least the 1st year after surgery. The development of donor-specific HLA antibodies should probably also be followed prospectively, even if at present there would be no specific therapy protocol in patients becoming antibody positive.

There is no current effective therapy for BO/BOS. Once the diagnosis is established, a change of immunosuppressive therapy is often operated, most frequently to no avail. However, overimmunosuppression should be avoided in order not to trigger infectious events. A 3-6-month course of azithromycin is justified. GERD should be reevaluated and treated aggressively. All infectious episodes should be treated promptly. General supportive measures such as maintaining a correct nutritional status are important. In some circumstances, photopheresis or total lymphoid irradiation is proposed and able to stabilize lung function. In selected patients redo-LTX can be carried out.

In addition to representing a major obstacle to long-term survival, BOS also causes significant morbidity and loss of health-related QoL [119].

Historically, it has been believed that $\mathrm{BO} / \mathrm{BOS}$ is the equivalent of "chronic rejection." However, the understanding of chronic lung allograft dysfunction is continuously evolving and the term "chronic rejection" is currently intentionally avoided by many LTX specialists for several reasons (although "chronic rejection" is still an expression used by many patients and caregivers) [120]. First of all, it has become clear that alloimmune, nonalloimmune, and even autoimmune factors contribute to the development of BO/BOS; thus, $\mathrm{BO} / \mathrm{BOS}$ might be the final expression of ANY aggression to the lung allograft. Secondly, there are potentially several subtypes of $\mathrm{BO} / \mathrm{BOS}$. A subpopulation of $\mathrm{BO} / \mathrm{BOS}$ patients show airway neutrophilia and seem to respond relatively well to azithromycin (neutrophilic reversible airways disease). Another subpopulation of $\mathrm{BO} / \mathrm{BOS}$ patients do not present with airway neutrophilia, tend to show mainly airway fibrosis with less inflammation, and are believed to be unresponsive to azithromycin. Finally, recently, it has been recognised that there are still other types of lung disorders, for example, the recently described restrictive allograft syndrome (RAS), which contribute to the respiratory morbidity and mortality after LTX [121]. RAS is characterised by restrictive ventilatory defect, infiltrates on lung CT, and peripheral foci of inflammation and fibrosis. In general, RAS shows poorer survival than $\mathrm{BO} / \mathrm{BOS}$. For all these reasons, the term chronic lung allograft dysfunction (CLAD) has been coined in order to include all these entities.

5.5. Infections in the Context of Immune Suppression. LTX recipients have a higher risk of infectious complications than recipients of other solid organs because of the constant exposure of the lungs to the environment, altered cough mechanism, bronchial circulation, lymphatic drainage, and the intensity of immunosuppression, which induces a state of persistent T- and B-cell dysfunction.

Infections (particularly pulmonary infections) are a frequent complication after LTX and constitute the major cause of patient morbidity and mortality [122]. Respiratory tract infections are the most common type of infection after LTX, with bacterial pneumonias being the leading cause in this category. CMV is the second most common infection followed by fungal and mycobacterial infections.

A timetable of infections-dividing the post-LTX era into 3 periods - can be established (Table 5). This categorisation is not absolute and infections may be distributed among alternative periods, particularly depending on underlying prophylactic and immune suppressive regimes [123].

In the early period (1st postoperative month) nosocomial infections due to bacteria and yeasts that might be observed in other surgical patients and infections due to classical CF pathogens are most frequent.

CF-specific pathogens persist in the paranasal sinuses and upper airways and may cause infectious episodes. As stated above many LTX centres refute CF patients harbouring Bcc, notably $B$. cenocepacia and B. gladioli because these pathogens are prone to cause immediate invasive disease with pneumonia, empyema, septicaemia, and death. Favourable long-term results in $B$. cenocepacia-positive patients are only reported in individual cases [124]. B. gladioli, moreover, may cause skin or soft tissue infections (i.e., sternum, chest wall, and mediastinum) as well as sepsis $[124,125]$. The survival for B. gladioli-positive patients after LTX is significantly lower than for patients with or without Bcc (with the exception of $B$. cenocepacia) [32, 126]. The reported incidence of NTM infection post-LTX is variable. Pulmonary infiltrations and/or infections of skin and soft tissue (e.g., sternal abscess, mediastinitis) predominate.

CF LTX recipients may suffer from nosocomial infection, including respiratory tract, urinary tract, skin and soft tissue, and catheter infections, or septic courses during hospitalisation. Respiratory tract and catheter-related infections are the major cause for bacteremia or sepsis. The immune suppression (induction therapy), "medical devices," and the administration of broad-spectrum antibiotics (typically selected to cover a patient's individual spectrum of 
TABLE 5: Timetable of infections following LTX.

\begin{tabular}{|c|c|c|}
\hline 1st month & 2nd-6th month & $>6$ months \\
\hline $\begin{array}{l}\text { Nosocomial infections }^{*} \\
\text { Respiratory tract infections } \\
\text { Surgical site infections } \\
\text { Urinary tract infections } \\
\text { Catheter infection, sepsis }\end{array}$ & $\begin{array}{l}\text { Reactivation of latent } \\
\text { infections + opportunistic } \\
\text { infections }\end{array}$ & $\begin{array}{l}\text { Community-acquired } \\
\text { infections/pneumonia }\end{array}$ \\
\hline $\begin{array}{l}\text { Related more to surgery and } \\
\text { intensive care }\end{array}$ & \multicolumn{2}{|c|}{ Related more to immunosuppression } \\
\hline $\begin{array}{l}\text { CF lung pathogens: } \\
\text { Pseudomonas spp. } \\
\text { Burkholderia cepacia complex } \\
\text { B. gladioli; NTM }\end{array}$ & $\begin{array}{l}\text { Viruses: } \\
\text { Cytomegalovirus } \\
\text { Epstein-Barr virus } \\
\text { Herpes simplex virus } \\
\text { Varicella Zoster virus }\end{array}$ & $\begin{array}{l}\text { Viruses: } \\
\text { Epstein-Barr virus } \\
\text { Respiratory viruses }\end{array}$ \\
\hline $\begin{array}{l}\text { Other bacteria: } \\
\text { S. aureus } \\
\text { Enterobacteriaceae } \\
\text { Enterococci } \\
\text { Acinetobacter spp. }\end{array}$ & $\begin{array}{l}\text { Opportunists: } \\
\text { P. jirovecii } \\
\text { Toxoplasmosis } \\
\text { Aspergillus spp. } \\
\text { Nocardia }\end{array}$ & $\begin{array}{l}\text { Respiratory bacteria: } \\
\text { S. pneumonia } \\
\text { H.influenzae } \\
\text { C. pneumoniae } \\
\text { M. pneumoniae } \\
\text { and others }\end{array}$ \\
\hline $\begin{array}{l}\text { Fungi: } \\
\text { Candida spp. } \\
\text { (Aspergillus spp.) }\end{array}$ & $\begin{array}{l}\text { Listeria } \\
\text { Mycobacteria } \\
\text { (especially NTM) }\end{array}$ & $\begin{array}{l}\text { CF lung pathogens: } \\
\text { Pseudomonas spp. } \\
\text { Burkholderia spp. }\end{array}$ \\
\hline $\begin{array}{l}\text { Viruses: } \\
\text { Herpes simplex virus } \\
\text { Respiratory viruses } \\
\end{array}$ & $\begin{array}{l}\text { CF-lung pathogens: } \\
\text { Pseudomonas spp. } \\
\text { Burkholderia spp. }\end{array}$ & $\begin{array}{l}\text { Fungi: } \\
\text { Aspergillus spp. }\end{array}$ \\
\hline & & $\begin{array}{l}\text { Late-onset C. difficile } \\
\text { infection }\end{array}$ \\
\hline
\end{tabular}

* May occur also in later periods after LTX depending on prolonged or recurrent hospitalisation and the presence of medical devices.

** Highest incidence within the first 3 up to 12 months after LTX in association with broad antimicrobial therapy and intense immunosuppression.

CF pathogens and their resistance phenotypes prior to transplantation) are major risk factors. Thus, the relevant pathogens comprise frequent nosocomial Gram-positive and Gram-negative bacteria such as $S$. aureus (MRSA/MSSA), Enterococci, Enterobacteriaceae (e.g., E. coli, Klebsiella spp., Enterobacter spp., etc.), P. aeruginosa, Acinetobacter spp., and mainly Candida spp. [126-129].

In the middle period (2-6 months after surgery) immunosuppression is maximal and this may in particular trigger reactivation of latent pathogens that were present in the lung donor or in the LTX recipient before surgery. Consequently, infections due to immunomodulating viruses (CMV, EBV, human herpesvirus 6 , and hepatitis B and C) and opportunistic infections (by pathogens such as Aspergillus spp., Pneumocystis jirovecii, and Listeria monocytogenes) predominate.

Cytomegalovirus (CMV) belongs to the herpes virus family and, after bacterial pneumonia, constitutes the second most common cause of infection in LTX recipients [130].

The risk of CMV infection is related to the recipient's pretransplant serological status, degree of immunosuppression, and type of antiviral prophylaxis during the early transplant period.

While short-term mortality in acute CMV infection has been reduced by CMV-killing virustatic agents, the indirect immunological effects of CMV infection predispose to CLAD [131].
CMV infection must be differentiated from CMV disease. CMV infection is characterised by an asymptomatic state of virus replication on clinical chemistry, whereas CMV disease signifies virus replication, clinical symptoms (e.g., fever, myalgias, and arthralgias), and tissue-invasive end organ involvement. After LTX, CMV pneumonitis is the predominant manifestation of CMV disease, but CMV hepatitis, gastroenteritis, or colitis is also encountered. CMV retinitis is less frequent than in AIDS patients [132].

Serologic tests (CMV antigen pp65), quantitative and qualitative PCR examination (CMV-DNA-PCR) of blood and BAL fluids or tissue samples [133], are used to establish the diagnosis. Histopathology is the gold standard of diagnosis of CMV disease. Prophylactic or preemptive treatment of CMV is recommended between 3 and 12 months after LTX depending on donor-recipient matching, CMV-negative recipients of CMV-positive donor lungs being at the highest risk of developing disease.

Due to a high risk of CLAD, it is advisable to treat LTX patients already when diagnosed with asymptomatic CMV viremia [133].

The spectrum of Aspergillus-related infections ranges from simple colonisation to invasive tracheobronchitis to invasive pulmonary or disseminated aspergillosis [134].

Invasive tracheobronchitis is particularly dangerous in the early postoperative period when it may affect 
the bronchial suture, compromising its healing withsometimes-disastrous effects such as fistula formation between bronchus and adjacent pulmonary artery [135]. Invasive pulmonary and disseminated forms are seen mostly later on [136, 137]. Risk factors for invasive aspergillosis include colonisation prior to LTX, extensive ischemia and necrosis of the bronchial anastomoses, CMV infection, high-dose steroid therapy, and increased maintenance immunosuppression in the context of CLAD.

Preventive management is carried out up to six months after LTX or at times of increased immunosuppression; there are no standardised protocols, but individually targeted approaches have been described [138].

Before the discovery of the novel triazole-antimycotics (e.g., voriconazole, posaconazole) invasive pulmonary or disseminated aspergillosis in a LTX recipient was uniformly fatal; these drugs are nowadays the treatment of choice and allow for a better prognostic outlook [139]. When prescribing these drugs particular attention should be paid for interactions with CNIs (CNI metabolism is inhibited by azoles and, thus, blood levels increase significantly) and other drugs metabolised via the CYP3A4 enzyme cascade. Echinocandins or lipid formulations of amphotericin B are potential, but less effective, substitutes [137].

All solid organ transplant recipients are at a high risk for Pneumocystis jirovecii $(\mathrm{Pj})$ pneumonia, especially in the first posttransplant year. This pathogen may lead to a lifethreatening interstitial pneumonia. Continuous prophylactic administration of trimethoprim/sulfamethoxazole on 3 days of the week has very significantly reduced the incidence of $\mathrm{Pj}$ pneumonia after LTX, which nowadays is very rare. Pneumocystis and/or trophozoites are visualised in BAL by Grocott's or Giemsa's staining; PCR-based methods are also available to ascertain the diagnosis of $\mathrm{Pj}$ pneumonia. Highdose trimethoprim/sulfamethoxazole is the treatment of choice; concomitant steroid therapy is required if the patient is hypoxemic [140]. Side effects are common, particularly at the high doses of trimethoprim/sulfamethoxazole used in therapy (severe rash, associated with fever, cytopenia, and deterioration of kidney function). Alternatives, but less effective, are nebulised pentamidine, oral dapsone, or atovaquone suspension.

C. difficile is isolated from stool specimens in $30-50 \%$ of CF patients, considerably more often than in other patient groups. In the first year after LTX, CF patients are 2-3 times more susceptible to $C$. difficile-associated diarrhoea and colitis than non-CF patients [141]. Severe colitis is a rare but classical cause of death in CF LTX recipients [142, 143]. C. difficile infection, however, may establish also after years mostly in the context of intensified immunosuppression due to graft rejection [144].

5.5.1. Respiratory Syncytial Virus Infection. RSV infection after LTX has prevalence of up to $20 \%$ and, along with acute morbidity, is an independent risk factor for the development of CLAD. Diagnosis is made by detection of virus replication (RSV-DNA-PCR) in nasopharyngeal specimens. Treatment is primarily carried out with ribavirin (if available) or an increased dose of steroids [145].
Onset in the late period is mainly associated with increased immune suppression in the context of CLAD.

5.6. Malignancies and Lymphoproliferative Diseases. Solid organ TX, independent of the underlying disease, increases the risk of malignancy by three- to four-fold. After LTX, the Registry of the ISHLT reports that $28 \%$ of ten-year survivors developed a malignant disease [146]. The risk of malignancy increases with time. In CF LTX recipients the risk of cancer is about six times higher than in the general population, with a substantial incidence of tumours involving the gastrointestinal tract (21-fold), skin and lymphoproliferative diseases (44fold) [147]. There are no specific guidelines for the prevention of malignant disease after LTX. It is recommended to follow at least the guidelines for the general population. Additionally, consistent application of sunscreen, avoidance of overexposure to sunlight, and regular dermatological checks are advised to prevent skin tumours. Regular screening colonoscopies, probably to be started at an earlier age than in the general population, may identify premalignant colonic lesions and prevent progression to malignancy [148].

\subsubsection{Posttransplantation Lymphoproliferative Disease} (PTLD). PTLD denotes various lymphoproliferative diseases (including lymphomas) occurring after TX and affecting 2$8 \%$ of the adult transplant recipients. PTLD occurs typically in the context of Epstein-Barr virus (EBV) infection or reactivation, which leads to immortalisation of EBV-infected B cells. Immunosuppression after TX inhibits T cell-mediated control of these cells leading to lymphoproliferation.

The risk for PTLD is particularly high in EBVseronegative recipients of EBV sero-positive donor lungs ( $\sim 30 \%$ compared to $<5 \%$ in sero-positive LTX recipients), which also explains the even higher risk for transplanted children. Other risk factors include the type of induction therapy and the intensity of immunosuppression. PTLD can be asymptomatic in the early stages and symptoms may remain nonspecific thereafter. Imaging studies are performed according to the patients' complaints, definite diagnosis is made by histology, and the disease is categorised according to WHO recommendations [149].

Clinically, two different courses of PTLD can be distinguished. Early PTLD is observed during the first year after LTX, with frequent intrathoracic manifestations and a mostly polyclonal histology. Delayed PTLD appears later and often outside the allograft and tends to be EBV negative. Its prognosis is poorer. The most important treatment options for PTLD include reduction of immune suppression (if possible), administration of an anti-CD20 antibody (rituximab) (if the PTLD is a B cell disease), and/or chemotherapy [150]. Rescue therapies consist of autologous/allogenic stem cell transplantations.

\section{Other Topics}

6.1. Physiotherapy Intervention. Physiotherapy before and following LTX includes respiratory management, physical and functional rehabilitation, and education. Short-term and long-term goals need to be set. 
The goal of intensified physiotherapy prior to LTX is to maintain the waitlisted patient in a clinically optimal condition for surgery. Apart from improving chest mobility and airway clearance, an individually tailored exercise program to improve functional capacity is usually started. Such a program may include aerobic conditioning as well as exercises to increase strength, flexibility, and/or balance/coordination. After LTX the main goal is to lessen chest pain and discomfort caused by the clamshell incision, improve breathing and cough while improving physical fitness as quickly as possible to avoid immobilisation, and to allow the patient to perform everyday activities [151].

6.1.1. Types of Physical Training. Physical training is defined as participation in a program of regular vigorous activity designed to improve physical performance or cardiovascular function or muscle strength or any combination of these three [152]. In general, people with CF can benefit from a wide range of different training modalities, for example, aerobic, anaerobic, and strength-training. Short- and longterm aerobic and/or anaerobic training have been proven to result in positive effects on lung function, aerobic fitness, strength, and quality of life [153-155].

In people with severely impaired pulmonary function and muscle wasting, interval training or moderate strength training might be better tolerated than continuous aerobic exercises. Although the evidence is sparse, support by oxygen supplementation [156] and noninvasive ventilation may allow/facilitate physical training in patients with severely altered respiratory function.

Aerobic training may include cycling or walking for a prescribed length of time at a targeted intensity, or interval training. Often, aerobic training intensity is based on a standardised exercise test. Some rehab facilities use the steep ramp test originally developed for cardiac rehabilitation [157] to guide interval training. This approach has been adopted for rehab in pulmonary diseases [158] and also used successfully in CF patients before and after LTX [159].

Although the data on severely ill patients is limited, clinical experience shows that supervised strength training is feasible and safe and sometimes better tolerated than endurance type exercises. Sufficient time for recovery, that is, more than 48 hours, is required following an intense training session.

6.1.2. Before TX. Standardised exercise testing is routinely used in the pretransplant assessment [160-162]. Currently, most centres employ the 6-minute walk test [161]. However, other exercise tests, including full cardiopulmonary exercise testing, are also used and may provide additional information $[161,162]$. Besides providing prognostic information [160, $162]$, the exercise test can guide advice on exercise training and conditioning during the waiting period and during posttransplant rehabilitation.

Preoperative rehabilitation aims to achieve optimum conditioning with regard to strength, endurance, mobility in everyday life and nutritional condition, at creating a better starting point for the transplantation thereby making for a better postoperative outcome [163].
The poorer a patient's condition is, the more he/she is going to benefit from an individually adjusted training program [164]. Preoperative rehabilitation may furthermore add to the selection of appropriate candidates or to the determination of the listing point. Contraindications for LTX - which previously were gone unnoticed-may become obvious during rehab. In many cases prior to LTX, CF patients do not meet the defined criteria for rehabilitation. Cardiopulmonary performance is frequently restricted to the extent of immobility, and the patients are incapable of taking care of themselves. Pulmonary rehabilitation must be oriented along the individual limitations and capacities of the LTX candidates, and this can only be done in specialised centres. Disease-specific features have to be taken into account, for example, bacterial colonisation in CF patients.

Besides the inhalation treatment and airway clearance sessions, patients should have access to exercise training three times a week in order to ensure that they are in an optimal condition for surgery. The individualised programme needs to be regularly reviewed by an expert physiotherapist or exercise specialist and regular assessments are required to adjust the programme to possible improvements in fitness or deterioration of general health.

6.1.3. After TX. Physiotherapy programs should be initiated in the ICU setting. Early mobilisation and daily physiotherapy is essential [165], taking into account the individual limitations of performance. The benefits of postoperative rehabilitation after LTX include reduced dyspnoea and subjectively an improved general condition [166]. A clinically relevant improvement of the walking distance (6-minute walk test) [167] and improved QoL after LTX [168] can be accomplished by individualised endurance and strength training.

Physiotherapy and respiratory therapy play a key role for patients with CF even after the transplantation. Aside from improving the elimination of secretions in the early postoperative period, it is essential to counteract limited ventilation due to thoracic restriction and pain related to scars/contractures. Conditioned pathologic breathing patterns must be compensated by correcting the patients' respiratory perception. This is also paramount since perception in the transplanted organ had been reduced by surgical denervation $[169,170]$.

After successful transplantation, physiotherapy must be continued past the period of early rehabilitation. Patients falsely overestimate their performance after LTX [166]. Continued resistance workouts are important to counterbalance the effects of long-term steroid intake.

6.2. Other Solid Organ Transplantations in CF (Heart, Liver, Kidney, and Pancreas). Heart-lung transplant is a major procedure that carries a high risk of complications. It is rarely performed in CF at present due to the fact that after bilateral lung transplantation myocardial recovery from right heart failure is dramatic and obviates the need for cardiac replacement [171].

The occurrence of liver disease in CF (CFLD) is specified at $27-35 \%$ by age of 18 years [172]. Incidence is at 2.5 per 100 patient years in the first ten years of life, with a prominent 
decline in the second decade. $5-10 \%$ of all patients will develop multilobular cirrhosis [173]. Liver transplantation (LiTX) is the treatment of choice in advanced CFLD. The indication for this procedure in CF differs compared to other diseases with chronic hepatic failure. Extrahepatic factors have to be considered as well, for example, progressive deterioration of nutritional condition (catabolism) and particularly pulmonary factors such as deteriorated lung function and an increased number of pulmonary exacerbations. Paediatric patients will benefit from early LiTX with improved lung function, since pulmonary alterations are more likely to be reversible in them than in adults. Given that particularly in CF disease severity and urgency of transplantation cannot be defined by common scoring systems like MELD (model of end-stage liver disease) or PELD score for paediatric patients [174], CF was added to the group of "standard exceptions" (exceptional and match-MELD score) to facilitate a better allocation of donor organs and improve the chance of a timely transplantation. Indication is clear in case of progressive hepatic dysfunction, uncontrollable ascites and variceal hemorrhages, hepatopulmonary syndrome, severe malnutrition. reduced QoL, and declining lung function due to advancing decompensation. A typical contraindication is poor pulmonary function. The threshold value for LiTX alone has been set empirically rather than evidence based at $\mathrm{FEV}_{1} / \mathrm{FVC}$ $<50 \%$ [175-177]. In any case, LiTX should be performed before lung function declines significantly. Immunosuppressive therapy does not differ here from other LiTX patients; however, CF patients show fluctuating drug levels more frequently and may require closer monitoring. CF patients develop diabetes mellitus more frequently than others after LiTX, whereas the prevalence of reduced renal function at 2 and 5 years is similar to that of LiTX recipients without CF [177]. CFLD treatment and liver transplantation have a positive effect on lung function in both children and adults; the long-term course of lung function is not truly influenced by LiTX, though, and matches that of patients without CFLD [178]. Inversely, CFLD does not constitute a contraindication to planned LTX, provided that hepatocellular function is conserved and portal hypertension is controlled [179].

In rare cases combined liver and lung transplantation has been performed, but the risk of perioperative complications is high and larger series are not available $[180,181]$. In one small series the overall survival of those receiving a combined liver and lung transplantation was 70\% at one and three years [181].

In rare instances a CF patient requires combined or sequential lung and kidney transplantation [182]. There are some reports on transplantations of pancreas, simultaneous liver-pancreas, or lung-pancreas $[183,184]$.

However, a recent meta-analysis of abdominal organ transplantation in CF concludes that pancreatic transplantation in CF is not an established procedure [185].

6.3. Pregnancy after Lung Transplantation. Successful pregnancy is possible after lung transplant, even among recipients with a diagnosis of cystic fibrosis [186]. However, these pregnancies are high-risk and require close maternal and fetal surveillance through coordinated care among maternalfetal medicine specialists and transplant personnel. Little is known about how the profound immunologic changes associated with pregnancy influence tolerance or rejection of the allograft and lung recipients appear at greatest risk for poorer pregnancy outcomes. Recipients should be in general good health and there should be optimal control of comorbid conditions such as liver function and diabetes prior to conception. Graft function should be stable and rejection-free. During pregnancy, maintenance-medication regimens should be continued with vigilant monitoring for effective drug levels and drug side effects with appropriate dose adjustment. Transplant professionals have to be aware of any additional risk to the fetus from immunosuppressive medications relative to the potential improvement in maternal graft function/survival conferred by each of these agents (e.g., mycophenolic acid is associated with a $23 \%$ incidence of birth defects) [187].

With the constant advent of new developments and modifications in immunosuppressive regimens, clinicians are responsible for providing pregnancy counselling to all preand posttransplant recipients of childbearing age. Caregivers have to be aware of how they relay the data and appreciate how recipients will process this information in order to make an informed decision regarding parenthood after transplantation, even in the face of potential risks. Ultimately, the patient has to be given the opportunity to make the decision [188].

6.4. Patient Education and Learning Objectives after LTX. After lung transplantation, CF patients have to acquire a lot of new skills to manage their life with a new chronic condition: adjust to new therapy, nutrition, and care regimens; manage new medications and risks; and control new emergency situations like rejection and infection. Multidisciplinary transplant teams should offer structured patient-centred education programs, with training sessions ensuring that the patient will be able to effectively manage unpredictable situations, especially those jeopardizing the outcome of the graft. Education can be facilitated by visual aids and written booklets.

Some learning objectives are crucial and should be acquired between the time of transplant and the first return home (Table 6) $[189,190]$. Detailed explanations should be provided as to the mechanism of action/absorption of immunosuppressive drugs and their anticipated side effects, the need for prophylactic anti-infectious therapy, and drugdrug and drug-food interactions. Patients with CFRD should receive ongoing diabetes self-management education, and education about the symptoms, prevention, and treatment of hypoglycemia is recommended for patients with CFRD and their care partners [191].

Other learning objectives should be addressed in the rehabilitation clinic and during the post-LTX outpatient visits, tailored to the patient situation and needs (e.g., importance of hydration and quantity of dietary salt, environmental risk factors, use of contraception, and prevention of sexually transmitted diseases, etc.) [192]. The use of knowledge questionnaires and other tools like clinical cases and scenarios facilitates the achievement of these objectives.

Finally, attention should be given to socioeconomic conditions and regular meetings with the social worker should 
TABLE 6: Learning objectives for the time between LTX and first return home.

(i) Identify warning signs of a change in respiratory status (including results of spirometry/PFT)

(ii) Respond to warning signs of a change in respiratory status

(iii) Describe the vital nature of immunosuppressants (role, mode of action, lifelong therapy, importance of biological monitoring)

(iv) Comply with proper handling of immunosuppressants

(v) State the role and mode of action of other medications

(vi) Respond to forgetting a medicine or to vomiting

(vii) Manage the stock of drugs and equipment

(viii) Identify food-related risks

(ix) Prevent skin diseases in the context of immunosuppression (sun exposure)

(x) Share their projects and activities, express their fears, desires, talk about body image, and manage stress, emotions, and so forth (life skills).

(xi) Know the risks of travelling

be scheduled to help patients manage their time when they resume work. Partners and close family members or friends are of great help for transplant recipients and can be invited to attend some of the education sessions.

\section{Conflict of Interests}

The authors declare that they have no conflict of interests regarding the publication of this paper.

\section{Acknowledgments}

This study is on behalf of the European Centres of Reference Network for Cystic Fibrosis (ECORN-CF) Study Group. This document is the result of the "European Centres of Reference Network for Cystic Fibrosis" (ECORN-CF) project, which was cofunded by the European Community from May 1, 2007, until April 30, 2010. Since then, ECORN-CF has been generously supported by the European Cystic Fibrosis Society, Cystic Fibrosis Europe, the patient organisations Association Belge de Lutte contre la Mucoviscidose, Mukoviszidose e.V., Vaincre La Mucoviscidose, and by the Christiane Herzog Foundation. The aim of the project has been to allow patients and care team members easy access to expert knowledge and advice on cystic fibrosis via an internet-based platform. All collaborating partner countries provide expert advice to their patients and care team members in their mother language on a local website. After translation of questions and answers into English and a quality check, they are published in a Central Archive with open access for everybody who is interested in the topic (www.ecorn-cf.eu). Thus, there is a transfer of knowledge and expertise throughout Europe that guarantees the same level of expert advice in all partner countries. Furthermore the program aimed to extract data on deficits in existing guidelines or lack of evidence-based guidelines and to find a European consensus for care of CF patients where it is necessary. Special thanks go to Annette
Pfalz and also Sophie Buchberger for the outstandingly smooth coordination of the whole project, the organisation of the consensus meetings, and the assistance with translation and linguistic revision of the paper. Furthermore, the authors would like to thank the European CF Nutrition Group who supported Dee Shimmin in the preparation of the nutrition sections in the paper. ECORN-CF study group members are Becher Thomas, Schillerhöhe Hospital, Gerlingen, Germany; Bell Scott, Adult Cystic Fibrosis Centre, The Prince Charles Hospital, Chermside, Australia; Blaas Stefan H., Center for Pneumology, Donaustauf Hospital, Donaustauf, Germany; Buchberger Sophie, Department of Pneumology, Goethe University Hospital Frankfurt, Germany; Carson Lesley, Belfast, UK; Danner-Boucher Isabelle, National Reference Centre for Cystic Fibrosis, Nantes University Medical Center, Nantes, France; David Valérie, National Reference Centre for Cystic Fibrosis, Nantes University Medical Center, Nantes, France; De Rijcke Karleen, CF Europe, Brussels, Belgium; Dieninghoff Doris, Lung Center Cologne, Department of Pneumology, Kliniken der Stadt Köln gGmbH, University of Witten/Herdecke; Duff Alistair, Clinical \& Health Psychology, Leeds Teaching Hospitals NHS Trust, Leeds, UK; Dumčius Sigitas, Department of Human and Medical Genetics, Vilnius University, Lithuania; Dupont Lieven, CF Centre, University Hospital Leuven, Belgium; Firlei-Fleischmann Natalie, Paracelsus Medical University, Department of Pulmonary Medicine, Salzburg, Austria; Fischer Rainald, Department of Pneumology, University of Munich, Munich, Germany; Gleiber Wolfgang, Department of Pneumology, Goethe University Hospital Frankfurt, Germany; Gottlieb Jens, Department of Respiratory Medicine OE 6870, Hannover Medical School, Germany; Hammermann Jutta, CF Centre, University Children's Hospital, Technical University Dresden, Dresden, Germany; Jaksch Peter, Department of Thoracic Surgery, Medical University Vienna, Vienna General Hospital, Vienna, Austria; Kahl Barbara C., University Hospital Münster, Institute of Medical Microbiology, Münster, Germany; Kanaan Reem, Pulmonology Department, Cystic Fibrosis Clinic, Cochin Hospital, Paris, France; Kerbrat Marythé, CF Reference Centre of NantesRoscoff, France; Kirsch Holger, Social Medicine, Psychoanalysis, Department of Social Work, University of Applied Sciences, Darmstadt, Germany; Lais Christoph, Department of Pneumology, Karlsruhe City Hospital, Germany; Lang György, Department of Thoracic Surgery, Medical University Vienna, Vienna General Hospital, Vienna, Austria; Lessire Fred, Medical Rehabilitation Center Zeepreventorium, De Haan, Belgium; Mainz Jochen G., Jena University Hospital, CF Centre, Pediatric Pneumology, Jena, Germany; Matossian Araxie, Department of Medical Psychology, Erasme University Hospital, Brussels, Belgium; Mayer Konstantin, Department of Internal Medicine, Lung Center, Justus-Liebig University Giessen, Giessen, Germany; Morrison Lisa, West of Scotland Adult Cystic Fibrosis Unit, Gartnavel General Hospital, Glasgow, UK; Pfalz Annette, Department of Pneumology, Goethe University Hospital Frankfurt, Germany; Ravilly Sophie, Department of Pediatrics, Necker Hospital, Paris, France; Rosenberger Stefanie,Schillerhöhe Hospital, Gerlingen, Germany; Schwarz Carsten, CF Centre, Charité 
Berlin, Germany; Shaw Fiona, Adult Cystic Fibrosis Centre, The Royal Brompton Hospital, London, UK; Sommerburg Olaf, Division of Pediatric Pulmonology, University Children's Hospital and Translational Lung Research Centre Heidelberg (TLRC), Member of the German Center for Lung Research Heidelberg, Germany; Stanford Gemma, Adult Cystic Fibrosis Centre, The Royal Brompton Hospital, London, UK; Sutharsan Sivagurunathan, Department of Pneumology, Ruhrlandklinik, West German Lung Center, University Hospital Duisburg-Essen, Germany.

\section{References}

[1] J. D. Christie, L. B. Edwards, A. Y. Kucheryavaya et al., "The Registry of the International Society for Heart and Lung ransplantation: 29th adult lung and heart-lung transplant report2012," The Journal of Heart and Lung Transplantation, vol. 31, no. 10, pp. 1073-1086, 2012.

[2] J. B. Orens, M. Estenne, S. Arcasoy et al., "International Guidelines for the Selection of Lung Transplant Candidates: 2006 Update-A Consensus Report From the Pulmonary Scientific Council of the International Society for Heart and Lung Transplantation," The Journal of Heart and Lung Transplantation, vol. 25, no. 7, pp. 745-755, 2006.

[3] T. G. Liou, F. R. Adler, and D. Huang, "Use of lung transplantation survival models to refine patient selection in cystic fibrosis," The American Journal of Respiratory and Critical Care Medicine, vol. 171, no. 9, pp. 1053-1059, 2005.

[4] J. Gottlieb, M. Ballmann, C. Von Mallinckrodt et al., "Lung transplantation in cystic fibrosis-a position paper," Pneumologie, vol. 63, no. 8, pp. 451-460, 2009.

[5] A. T. Braun and C. A. Merlo, "Cystic fibrosis lung transplantation," Current Opinion in Pulmonary Medicine, vol. 17, no. 6, pp. 467-472, 2011.

[6] Bekanntmachung der Bundesärztekammer, "Richtlinien zur Organtransplantation gem. $₫ 16$ Abs. 1 S. 1 Nrn. 2 u. 5 TPG," Deutsches Ärzteblatt, vol. 108, pp. B2037-B2054, 2011.

[7] J. De Meester, J. M. A. Smits, G. G. Persijn, and A. Haverich, "Listing for lung transplantation: life expectancy and transplant effect, stratified by type of end-stage lung disease, the Eurotransplant experience," The Journal of Heart and Lung Transplantation, vol. 20, no. 5, pp. 518-524, 2001.

[8] J. R. ) Maurer, A. E. Frost, M. Estenne, T. Higenbottam, and A. R. Glanville, "International guidelines for the selection of lung transplant candidates. The International Society for Heart and Lung Transplantation, the American Thoracic Society, the American Society of Transplant Physicians, the European Respiratory Society," The Journal of Heart and Lung Transplantation, vol. 17, no. 7, pp. 703-709, 1998.

[9] T. M. Egan, S. Murray, R. T. Bustami et al., "Development of the new lung allocation system in the United States," The American Journal of Transplantation, vol. 6, no. 5, pp. 1212-1227, 2006.

[10] H. Chen, S. C. Shiboski, J. A. Golden et al., "Impact of the lung allocation score on lung transplantation for pulmonary arterial hypertension," The American Journal of Respiratory and Critical Care Medicine, vol. 180, no. 5, pp. 468-474, 2009.

[11] A. R. Glanville and M. Estenne, "Indications, patient selection and timing of referral for lung transplantation," European Respiratory Journal, vol. 22, no. 5, pp. 845-852, 2003.
[12] J. Gottlieb, F. Mattner, H. Weissbrodt et al., "Impact of graft colonization with gram-negative bacteria after lung transplantation on the development of bronchiolitis obliterans syndrome in recipients with cystic fibrosis," Respiratory Medicine, vol. 103, no. 5, pp. 743-749, 2009.

[13] J. G. Mainz, L. Naehrlich, M. Schien et al., "Concordant genotype of upper and lower airways $\mathrm{P}$ aeruginosa and $\mathrm{S}$ aureus isolates in cystic fibrosis," Thorax, vol. 64, no. 6, pp. 535-540, 2009.

[14] J. G. Mainz, J. Hentschel, C. Schien et al., "Sinonasal persistence of Pseudomonas aeruginosa after lung transplantation," Journal of Cystic Fibrosis, vol. 11, no. 2, pp. 158-161, 2012.

[15] S. Walter, P. Gudowius, J. Boßhammer et al., "Epidemiology of chronic Pseudomonas aeruginosa infections in the airways of lung transplant recipients with cystic fibrosis," Thorax, vol. 52, no. 4, pp. 318-321, 1997.

[16] J. R. Yankaskas and G. B. Mallory Jr., "Lung transplantation in cystic fibrosis: consensus conference statement," Chest, vol. 113, no. 1, pp. 217-226, 1998.

[17] M.-K. Leung, L. Rachakonda, D. Weill, and P. H. Hwang, "Effects of sinus surgery on lung transplantation outcomes in cystic fibrosis," The American Journal of Rhinology, vol. 22, no. 2, pp. 192-196, 2008.

[18] T.-L. Fong, Y. W. Cho, L. Hou, I. V. Hutchinson, R. G. Barbers, and C. S. Herrington, "Outcomes after lung transplantation and practices of lung transplant programs in the united states regarding hepatitis C seropositive recipients," Transplantation, vol. 91, no. 11, pp. 1293-1296, 2011.

[19] A. B.-G. Shitrit, M. R. Kramer, I. Bakal, G. Morali, Z. B. Ari, and D. Shitrit, "Lamivudine prophylaxis for hepatitis B virus infection after lung transplantation," Annals of Thoracic Surgery, vol. 81, no. 5, pp. 1851-1852, 2006.

[20] P. A. Grossi, "Update in HIV infection in organ transplantation," Current Opinion in Organ Transplantation, vol. 17, no. 6, pp. 586-593, 2012.

[21] A. Bertani, P. Grossi, P. Vitulo et al., "Successful lung transplantation in an HIV-and HBV-positive patient with cystic fibrosis: case report," The American Journal of Transplantation, vol. 9, no. 9, pp. 2190-2196, 2009.

[22] J. W. Su, D. P. Mason, S. C. Murthy et al., "Successful double lung transplantation in 2 patients with severe scoliosis," The Journal of Heart and Lung Transplantation, vol. 27, no. 11, pp. 1262-1264, 2008.

[23] J. G. Allen, G. J. Arnaoutakis, E. S. Weiss, C. A. Merlo, J. V. Conte, and A. S. Shah, "The impact of recipient body mass index on survival after lung transplantation," The Journal of Heart and Lung Transplantation, vol. 29, no. 9, pp. 1026-1033, 2010.

[24] G. I. Snell, K. Bennetts, J. Bartolo et al., "Body mass index as a predictor of survival in adults with cystic fibrosis referred for lung transplantation," The Journal of Heart and Lung Transplantation, vol. 17, no. 11, pp. 1097-1103, 1998.

[25] R. R. Bartz, R. B. Love, G. E. Leverson, L. R. Will, D. L. Welter, and K. C. Meyer, "Pre-transplant mechanical ventilation and outcome in patients with cystic fibrosis," The Journal of Heart and Lung Transplantation, vol. 22, no. 4, pp. 433-438, 2003.

[26] G. Massard, H. Shennib, D. Metras et al., "Double-lung transplantation in mechanically ventilated patients with cystic fibrosis," Annals of Thoracic Surgery, vol. 55, no. 5, pp. 1087-1092, 1993.

[27] R. M. Aris, P. H. Gilligan, I. P. Neuringer, K. K. Gott, J. Rea, and J. R. Yankaskas, "The effects of panresistant bacteria in cystic 
fibrosis patients on lung transplant outcome," The American Journal of Respiratory and Critical Care Medicine, vol. 155, no. 5, pp. 1699-1704, 1997.

[28] D. Hadjiliadis, M. P. Steele, C. Chaparro et al., "Survival of lung transplant patients with cystic fibrosis harboring panresistant bacteria other than Burkholderia cepacia, compared with patients harboring sensitive bacteria," The Journal of Heart and Lung Transplantation, vol. 26, no. 8, pp. 834-838, 2007.

[29] V. Boussaud, R. Guillemain, D. Grenet et al., "Clinical outcome following lung transplantation in patients with cystic fibrosis colonised with Burkholderia cepacia complex: results from two French centres," Thorax, vol. 63, no. 8, pp. 732-737, 2008.

[30] B. D. Alexander, E. W. Petzold, L. B. Reller et al., "Survival after lung transplantation of cystic fibrosis patients infected with Burkholderia cepacia complex," The American Journal of Transplantation, vol. 8, no. 5, pp. 1025-1030, 2008.

[31] A. De Soyza, G. Meachery, K. L. M. Hester et al., "Lung transplantation for patients with cystic fibrosis and Burkholderia cepacia complex infection: a single-center experience," The Journal of Heart and Lung Transplantation, vol. 29, no. 12, pp. 1395-1404, 2010.

[32] S. Murray, J. Charbeneau, B. C. Marshall, and J. J. LiPuma, "Impact of Burkholderia infection on lung transplantation in cystic fibrosis," The American Journal of Respiratory and Critical Care Medicine, vol. 178, no. 4, pp. 363-371, 2008.

[33] K. D. Brizendine, J. W. Baddley, P. G. Pappas, K. J. Leon, and J. M. Rodriguez, "Fatal Burkholderia gladioli infection misidentified as Empedobacter brevis in a lung transplant recipient with cystic fibrosis," Transplant Infectious Disease, vol. 14, no. 4, pp. E13-E18, 2012.

[34] A. Olland, P.-E. Falcoz, R. Kessler, and G. Massard, "Should cystic fibrosis patients infected with Burkholderia cepacia complex be listed for lung transplantation?" Interactive Cardiovascular and Thoracic Surgery, vol. 13, no. 6, pp. 631-634, 2011.

[35] P. W. Jordan, T. Stanley, F. M. Donnelly et al., "Atypical mycobacterial infection in patients with cystic fibrosis: update on clinical microbiology methods," Letters in Applied Microbiology, vol. 44, no. 5, pp. 459-466, 2007.

[36] M. Gilljam, H. Scherstén, M. Silverborn, B. Jönsson, and A. Ericsson Hollsing, "Lung transplantation in patients with cystic fibrosis and Mycobacterium abscessus infection," Journal of Cystic Fibrosis, vol. 9, no. 4, pp. 272-276, 2010.

[37] R. Sharma, V. G. Florea, A. P. Bolger et al., "Wasting as an independent predictor of mortality in patients with cystic fibrosis," Thorax, vol. 56, no. 10, pp. 746-750, 2001.

[38] L. T. Beker, E. Russek-Cohen, and R. J. Fink, "Stature as a prognostic factor in cystic fibrosis survival," Journal of the American Dietetic Association, vol. 101, no. 4, pp. 438-442, 2001.

[39] M. Corey, F. J. McLaughlin, M. Williams, and H. Levison, "A comparison of survival, growth, and pulmonary function in patients with cystic fibrosis in Boston and Toronto," Journal of Clinical Epidemiology, vol. 41, no. 6, pp. 583-591, 1988.

[40] D. J. Lederer, J. S. Wilt, F. D'Ovidio et al., "Obesity and underweight are associated with an increased risk of death after lung transplantation," The American Journal of Respiratory and Critical Care Medicine, vol. 180, no. 9, pp. 887-895, 2009.

[41] J. Madill, C. Gutierrez, J. Grossman et al., "Nutritional assessment of the lung transplant patient: body mass index as a predictor of 90-day mortality following transplantation," The Journal of Heart and Lung Transplantation, vol. 20, no. 3, pp. 288-296, 2001.
[42] C. Schwebel, I. Pin, D. Barnoud et al., "Prevalence and consequences of nutritional depletion in lung transplant candidates," European Respiratory Journal, vol. 16, no. 6, pp. 1050-1055, 2000.

[43] L. Sharples, T. Hathaway, C. Dennis, N. Caine, T. Higenbottam, and J. Wallwork, "Prognosis of patients with cystic fibrosis awaiting heart and lung transplantation," The Journal of Heart and Lung Transplantation, vol. 12, no. 4, pp. 669-674, 1993.

[44] J. J. Egan, "Management of cystic fibrosis before and after lung transplantation," Journal of the Royal Society of Medicine, Supplement, vol. 90, no. 31, pp. 47-58, 1997.

[45] H. Naon, S. Hack, M. T. Shelton, R. C. Gotthoffer, and D. Gozal, "Resting energy expenditure: evolution during antibiotic treatment for pulmonary exacerbation in cystic fibrosis," Chest, vol. 103, no. 6, pp. 1819-1825, 1993.

[46] C. Tynan and J. M. Hasse, "Current nutrition practices in adult lung transplantation," Nutrition in Clinical Practice, vol. 19, no. 6, pp. 587-596, 2004.

[47] P. E. Pfeffer, J. M. Pfeffer, and M. E. Hodson, "The psychosocial and psychiatric side of cystic fibrosis in adolescents and adults," Journal of Cystic Fibrosis, vol. 2, no. 2, pp. 61-68, 2003.

[48] L. Goldbeck, T. Besier, A. Hinz, S. Singer, and A. L. Quittner, "Prevalence of symptoms of anxiety and depression in German patients with cystic fibrosis," Chest, vol. 138, no. 4, pp. 929-936, 2010.

[49] E. J. Burker, R. A. Carels, L. F. Thompson, L. Rodgers, and T. Egan, "Quality of life in patients awaiting lung transplant: cystic fibrosis versus other end-stage lung diseases," Pediatric Pulmonology, vol. 30, no. 6, pp. 453-460, 2000.

[50] J. L. Taylor, P. J. Smith, M. A. Babyak et al., "Coping and quality of life in patients awaiting lung transplantation," Journal of Psychosomatic Research, vol. 65, no. 1, pp. 71-79, 2008.

[51] J. Gottlieb, T. Welte, M. M. Höper, M. Strüber, and J. Niedermeyer, "Lung transplantation: potentials and limitations," Internist, vol. 45, no. 11, pp. 1246-1260, 2004.

[52] C. L. Woodman, L. J. Geist, S. Vance, C. Laxson, K. Jones, and J. N. Kline, "Psychiatric disorders and survival after lung transplantation," Psychosomatics, vol. 40, no. 4, pp. 293-297, 1999.

[53] A. Matossian, T. Havermans, N. Claes, and C. Knoop, "Anxiety and depression in CF patients after lung transplantation," Journal of Cystic Fibrosis, vol. 7, supplement 2, p. 106, 2008.

[54] R. M. Nobili, A. J. A. Duff, G. Ullrich et al., "Guiding principles on how to manage relevant psychological aspects within a $\mathrm{CF}$ team: interdisciplinary approaches," Journal of Cystic Fibrosis, vol. 10, supplement 2, pp. S45-S52, 2011.

[55] B. Johann and J. Lorenzen, "Die psychosomatische Evaluation von Lebertransplantationspatienten. Anwendungsmöglichkeiten der Transplant-Evaluation-Ratings-Scale," in Psychosomatische Betreuung von Transplantationspatienten, B. Johann and R. Lange, Eds., Pabst Science Publishers, Lengerich, Germany, 1997.

[56] J. M. Patterson, M. Wall, J. Berge, and C. Milla, "Gender differences in treatment adherence among youth with cystic fibrosis: development of a new questionnaire," Journal of Cystic Fibrosis, vol. 7, no. 2, pp. 154-164, 2008.

[57] G. Ullrich and K. Stahl, "Health care preferences and satisfaction in adolescents with CF", Journal of Cystic Fibrosis, vol. 9, supplement 1, pp. 99-103, 2010.

[58] L. Goetzmann, “'Is it me, or isn't it?'-transplanted organs and their donors as transitional objects," The American Journal of Psychoanalysis, vol. 64, no. 3, pp. 279-289, 2004. 
[59] C. Miller, C. Harris, G. Latchford, S. Conway, and D. Peckham, "Are the psychosocial needs of cystic fibrosis patients being met post-transplant?" Journal of Cystic Fibrosis, vol. 9, supplement 1, p. 104, 2010.

[60] C. Archonti, R. D’Amelio, T. Klein, H.-J. Schäfers, G. W. Sybrecht, and H. Wilkens, "Physical quality of life and social support in patients on the waiting list and after a lung transplantation," Psychotherapie Psychosomatik Medizinische Psychologie, vol. 54, no. 1, pp. 17-22, 2004.

[61] D. Ricci, M. Boffini, L. Del Sorbo et al., "The use of $\mathrm{CO}_{2}$ removal devices in patients awaiting lung transplantation: an initial experience," Transplantation Proceedings, vol. 42, no. 4, pp. 1255-1258, 2010.

[62] C. A. Bermudez, R. V. Rocha, D. Zaldonis et al., "Extracorporeal membrane oxygenation as a bridge to lung transplant: midterm outcomes," Annals of Thoracic Surgery, vol. 92, no. 4, pp. 12261232, 2011.

[63] G. Lang, S. Taghavi, C. Aigner et al., "Primary lung transplantation after bridge with extracorporeal membrane oxygenation: a plea for a shift in our paradigms for indications," Transplantation, vol. 93, no. 7, pp. 729-736, 2012.

[64] S. I. De Vleeschauwer, S. Wauters, L. J. Dupont et al., "Mediumterm outcome after lung transplantation is comparable between brain-dead and cardiac-dead donors," The Journal of Heart and Lung Transplantation, vol. 30, no. 9, pp. 975-981, 2011.

[65] C. H. Wigfield and R. B. Love, "Donation after cardiac death lung transplantation outcomes," Current Opinion in Organ Transplantation, vol. 16, no. 5, pp. 462-468, 2011.

[66] C. Aigner, A. Slama, K. Hötzenecker et al., "Clinical ex vivo lung perfusion-pushing the limits," The American Journal of Transplantation, vol. 12, no. 7, pp. 1839-1847, 2012.

[67] R. Ingemansson, A. Eyjolfsson, L. Mared et al., "Clinical transplantation of initially rejected donor lungs after reconditioning ex vivo," Annals of Thoracic Surgery, vol. 87, no. 1, pp. 255-260, 2009.

[68] M. Cypel, J. C. Yeung, L. Mingyao et al., "NOrmothermic ex vivo lung perfusion in clinical lung transplantation," New England Journal of Medicine, vol. 364, no. 15, pp. 1431-1440, 2011.

[69] C. Aigner, P. Jaksch, S. Taghavi et al., "Donor total lung capacity predicts recipient total lung capacity after size-reduced lung transplantation," The Journal of Heart and Lung Transplantation, vol. 24, no. 12, pp. 2098-2102, 2005.

[70] C. H. R. Boasquevisque, E. Yildirim, T. K. Waddel, and S. Keshavjee, "Surgical techniques: lung transplant and lung volume reduction," Proceedings of the American Thoracic Society, vol. 6, no. 1, pp. 66-78, 2009.

[71] P. D. Robinson, K. A. Harris, P. Aurora, J. C. Hartley, V. Tsang, and H. Spencer, "Paediatric lung transplant outcomes vary with Mycobacterium abscessus complex species," European Respiratory Journal, vol. 41, no. 5, pp. 1230-1232, 2013.

[72] C. L. Lau and G. A. Patterson, "Technical considerations in lung transplantation," Chest Surgery Clinics of North America, vol. 13, no. 3, pp. 463-483, 2003.

[73] C. Aigner, S. Mazhar, P. Jaksch et al., "Lobar transplantation, split lung transplantation and peripheral segmental resectionreliable procedures for downsizing donor lungs," European Journal of Cardio-Thoracic Surgery, vol. 25, no. 2, pp. 179-183, 2004.

[74] T. M. Egan, J. T. Thompson, F. C. Detterbeck et al., "Effect of size (mis)matching in clinical double-lung transplantation," Transplantation, vol. 59, no. 5, pp. 707-713, 1995.
[75] N. Shigemura, J. D’Cunha, J. K. Bhama et al., "Lobar lung transplantation: a relevant surgical option in the current era of lung allocation score," The Annals of Thoracic Surgery, vol. 96, no. 2, pp. 451-456, 2013.

[76] F. Chen, T. Fujinaga, T. Shoji et al., "Outcomes and pulmonary function in living lobar lung transplant donors," Transplant International, vol. 25, no. 2, pp. 153-157, 2012.

[77] C. Aigner, W. Wisser, S. Taghavi et al., "Institutional experience with extracorporeal membrane oxygenation in lung transplantation," European Journal of Cardio-thoracic Surgery, vol. 31, no. 3, pp. 468-474, 2007.

[78] N. Shigemura, J. Bhama, C. J. Gries et al., "Lung transplantation in patients with prior cardiothoracic surgical procedures," The American Journal of Transplantation, vol. 12, no. 5, pp. 12491255, 2012.

[79] J. D. Christie, M. Carby, R. Bag, P. Corris, M. Hertz, and D. Weill, "Report of the ISHLT Working Group on Primary Lung Graft Dysfunction part II: definition. A consensus statement of the International Society for Heart and Lung Transplantation," The Journal of Heart and Lung Transplantation, vol. 24, no. 10, pp. 1454-1459, 2005.

[80] B. A. Whitson, M. E. Prekker, C. S. Herrington et al., "Primary Graft Dysfunction and Long-term Pulmonary Function After Lung Transplantation," The Journal of Heart and Lung Transplantation, vol. 26, no. 10, pp. 1004-1011, 2007.

[81] K. C. Meyer, "Lung transplantation," F1000Prime Reports, vol. 5, p. 16, 2013.

[82] L. L. Schulman, T. Anandarangam, D. W. Leibowitz et al., "Four-year prospective study of pulmonary venous thrombosis after lung transplantation," Journal of the American Society of Echocardiography, vol. 14, no. 8, pp. 806-812, 2001.

[83] B. M. Fadel, K. Abdulbaki, V. Nambiar et al., "Dual thrombosis of the pulmonary arterial and venous anastomotic sites after single lung transplantation: role of transesophageal echocardiography in diagnosis and management," Journal of the American Society of Echocardiography, vol. 20, no. 4, pp. 438.e9-438.e12, 2007.

[84] E. S. Kahan, G. Petersen, J. P. Gaughan, and G. J. Criner, "High incidence of venous thromboembolic events in lung transplant recipients," The Journal of Heart and Lung Transplantation, vol. 26, no. 4, pp. 339-344, 2007.

[85] Y. Berk, W. van der Bij, M. E. Erasmus, and P. J. Wijkstra, "Noninvasive ventilation in phrenic nerve dysfunction after lung transplantation: an attractive option," The Journal of Heart and Lung Transplantation, vol. 25, no. 12, pp. 1483-1485, 2006.

[86] D. E. Maziak, J. R. Maurer, and S. Kesten, "Diaphragmatic paralysis: a complication of lung transplantation," Annals of Thoracic Surgery, vol. 61, no. 1, pp. 170-173, 1996.

[87] E. Fitzsullivan, C. J. Gries, P. Phelan et al., "Reduction in airway complications after lung transplantation with novel anastomotic technique," Annals of Thoracic Surgery, vol. 92, no. 1, pp. 309-315, 2011.

[88] J. F. Santacruz and A. C. Mehta, "Airway complications and management after lung transplantation: ischemia, dehiscence, and stenosis," Proceedings of the American Thoracic Society, vol. 6, no. 1, pp. 79-93, 2009.

[89] J. Puchalski, H. J. Lee, and D. H. Sterman, "Airway complications following lung transplantation," Clinics in Chest Medicine, vol. 32, no. 2, pp. 357-366, 2011.

[90] D. Hayes Jr. and H. M. Mansour, "Vanishing bronchus intermedius syndrome in a pediatric patient with cystic fibrosis after 
lung transplantation," Pediatric Transplantation, vol. 16, no. 8, pp. E333-E337, 2012.

[91] M. Paradela, D. González, I. Parente et al., "Surgical risk factors associated with lung transplantation," Transplantation Proceedings, vol. 41, no. 6, pp. 2218-2220, 2009.

[92] N. Pahwa and A. Hedberg, "Adult heart and lung transplantation," in Comprehensive Guide to Transplant Nutrition, J. M. Hasse and L. S. Blue, Eds., pp. 31-43, American Dietetic Association, Chicago, Ill, USA, 2002.

[93] J. M. Hasse, "Diet therapy for organ transplantation. A problembased approach," The Nursing clinics of North America, vol. 32, no. 4, pp. 863-880, 1997.

[94] D. Kalnins and M. Wilschanski, "Maintenance of nutritional status in patients with cystic fibrosis: new and emerging therapies," Drug Design, Development and Therapy, vol. 6, pp. 151-161, 2012.

[95] A. Stephenson, M. Brotherwood, R. Robert et al., "Increased vitamin $\mathrm{A}$ and $\mathrm{E}$ levels in adult cystic fibrosis patients after lung transplantation," Transplantation, vol. 79, no. 5, pp. 613615, 2005.

[96] T. Ho, S. Gupta, M. Brotherwood et al., "Increased serum vitamin A and e levels after lung transplantation," Transplantation, vol. 92, no. 5, pp. 601-606, 2011.

[97] D. Hadjiliadis, J. Madill, C. Chaparro et al., "Incidence and prevalence of diabetes mellitus in patients with cystic fibrosis undergoing lung transplantation before and after lung transplantation," Clinical Transplantation, vol. 19, no. 6, pp. 773-778, 2005.

[98] J. R. Yankaskas, B. C. Marshall, B. Sufian, R. H. Simon, and D. Rodman, "Cystic fibrosis adult care: consensus conference report," Chest, vol. 125, no. 1, pp. 1S-39S, 2004.

[99] M. Gilljam, C. Chaparro, E. Tullis, C. Chan, S. Keshavjee, and M. Hutcheon, "GI complications after lung transplantation in patients with cystic fibrosis," Chest, vol. 123, no. 1, pp. 37-41, 2003.

[100] C. Colombo, H. Ellemunter, R. Houwen, A. Munck, C. Taylor, and M. Wilschanski, "Guidelines for the diagnosis and management of distal intestinal obstruction syndrome in cystic fibrosis patients," Journal of Cystic Fibrosis, vol. 10, supplement 2, pp. S24-S28, 2011.

[101] E. Kerem, S. Conway, S. Elborn et al., "Standards of care for patients with cystic fibrosis: a European consensus," Journal of Cystic Fibrosis, vol. 4, no. 1, pp. 7-26, 2005.

[102] D. R. Snydman, A. P. Limaye, L. Potena, M. R. Zamora, and K. Weigand, "Update and review: state-of-the-art management of cytomegalovirus infection and disease following thoracic organ transplantation," Transplantation Proceedings, vol. 43, no. 3, supplement, pp. S1-S17, 2011.

[103] G. Belle-van Meerkerk, E. A. van de Graaf, J. M. Kwakkel-van Erp et al., "Diabetes before and after lung transplantation in patients with cystic fibrosis and other lung diseases," Diabetic Medicine, vol. 29, no. 8, pp. e159-e162, 2012.

[104] M. Hofer, C. Schmid, C. Benden et al., "Diabetes mellitus and survival in cystic fibrosis patients after lung transplantation," Journal of Cystic Fibrosis, vol. 11, no. 2, pp. 131-136, 2012.

[105] V. Mertens, L. Dupont, and D. Sifrim, "Relevance of GERD in lung transplant patients," Current Gastroenterology Reports, vol. 12, no. 3, pp. 160-166, 2010.

[106] M. G. Hartwig and R. D. Davis, "Gastroesophageal reflux disease-induced aspiration injury following lung transplantation," Current Opinion in Organ Transplantation, vol. 17, no. 5, pp. 474-478, 2012.
[107] R. D. Davis Jr., C. L. Lau, S. Eubanks et al., "Improved lung allograft function after fundoplication in patients with gastroesophageal reflux disease undergoing lung transplantation," Journal of Thoracic and Cardiovascular Surgery, vol. 125, no. 3, pp. 533-542, 2003.

[108] B. M. Mendez, C. S. Davis, C. Weber, R. J. Joehl, and P. M. Fisichella, "Gastroesophageal reflux disease in lung transplant patients with cystic fibrosis," The American Journal of Surgery, vol. 204, no. 5, pp. e21-e26, 2012.

[109] M. Peltz, L. B. Edwards, M. E. Jessen, F. Torres, and D. M. Meyer, "HLA mismatches influence lung transplant recipient survival, bronchiolitis obliterans and rejection: implications for donor lung allocation," The Journal of Heart and Lung Transplantation, vol. 30, no. 4, pp. 426-434, 2011.

[110] M. I. Hertz, P. Aurora, C. Benden et al., "Scientific registry of the international society for heart and lung transplantation: introduction to the 2011 annual reports," The Journal of Heart and Lung Transplantation, vol. 30, no. 10, pp. 1071-1077, 2011.

[111] T. Martinu, D.-F. Chen, and S. M. Palmer, "Acute rejection and humoral sensitization in lung transplant recipients," Proceedings of the American Thoracic Society, vol. 6, no. 1, pp. 54-65, 2009.

[112] D. Kumar, S. Husain, M. H. Chen et al., "A prospective molecular surveillance study evaluating the clinical impact of community-acquired respiratory viruses in lung transplant recipients," Transplantation, vol. 89, no. 8, pp. 1028-1033, 2010.

[113] S. Herber, J. Lill, C. P. Heussel, E. Mayer, M. Thelen, and H.-U. Kauczor, "Acute or chronic transplant rejection-high resolution CT of the chest in lung transplant recipients," RoFo Fortschritte auf dem Gebiet der Rontgenstrahlen und der Bildgebenden Verfahren, vol. 173, no. 9, pp. 822-829, 2001.

[114] S. Stewart, M. C. Fishbein, G. I. Snell et al., "Revision of the 1996 Working Formulation for the Standardization of Nomenclature in the Diagnosis of Lung Rejection," The Journal of Heart and Lung Transplantation, vol. 26, no. 12, pp. 1229-1242, 2007.

[115] A. R. Glanville, "Bronchoscopic monitoring after lung transplantation," Seminars in Respiratory and Critical Care Medicine, vol. 31, no. 2, pp. 208-221, 2010.

[116] M. Estenne, J. R. Maurer, A. Boehler et al., "Bronchiolitis obliterans syndrome 2001: an update of the diagnostic criteria," The Journal of Heart and Lung Transplantation, vol. 21, no. 3, pp. 297-310, 2002.

[117] V. G. Valentine, R. C. Robbins, G. J. Berry et al., "Actuarial survival of heart-lung and bilateral sequential lung transplant recipients with obliterative bronchiolitis," The Journal of Heart and Lung Transplantation, vol. 15, no. 4, pp. 371-383, 1996.

[118] R. Vos, B. M. Vanaudenaerde, N. Geudens, L. J. Dupont, D. E. Van Raemdonck, and G. M. Verleden, "Pseudomonal airway colonisation: risk factor for bronchiolitis obliterans syndrome after lung transplantation?" European Respiratory Journal, vol. 31, no. 5, pp. 1037-1045, 2008.

[119] J. W. K. van den Berg, A. Geertsma, W. van der Bij et al., "Bronchiolitis obliterans syndrome after lung transplantation and health-related quality of life," The American Journal of Respiratory and Critical Care Medicine, vol. 161, no. 6, pp. 19371941, 2000.

[120] C. Knoop and M. Estenne, "Chronic allograft dysfunction," Clinics in Chest Medicine, vol. 32, no. 2, pp. 311-326, 2011.

[121] M. Sato, T. K. Waddell, U. Wagnetz et al., "Restrictive allograft syndrome (RAS): a novel form of chronic lung allograft dysfunction," The Journal of Heart and Lung Transplantation, vol. 30, no. 7, pp. 735-742, 2011. 
[122] J. D. Christie, L. B. Edwards, A. Y. Kucheryavaya et al., "The registry of the international society for heart and lung transplantation: twenty-eighth adult lung and heart-lung transplant report-2011," The Journal of Heart and Lung Transplantation, vol. 30, no. 10, pp. 1104-1122, 2011.

[123] M. Green, "Introduction: infections in solid organ transplantation," The American Journal of Transplantation, vol. 13, supplement 4, pp. 3-8, 2013.

[124] E. F. Nash, A. Coonar, R. Kremer et al., "Survival of Burkholderia cepacia sepsis following lung transplantation in recipients with cystic fibrosis," Transplant Infectious Disease, vol. 12, no. 6, pp. 551-554, 2010.

[125] A. C. Church, P. Sivasothy, J. Parmer, and J. Foweraker, "Mediastinal abscess after lung transplantation secondary to burkholderia gladioli infection," The Journal of Heart and Lung Transplantation, vol. 28, no. 5, pp. 511-514, 2009.

[126] S. S. Kanj, V. Tapson, R. D. Davis, J. Madden, and I. Browning, "Infections in patients with cystic fibrosis following lung transplantation," Chest, vol. 112, no. 4, pp. 924-930, 1997.

[127] Z. Kovats, Z. Sütto, G. Muraközy et al., "Airway pathogens during the first year after lung transplantation: a single-center experience," Transplantation Proceedings, vol. 43, no. 4, pp. 1290-1291, 2011.

[128] R. San Juan, J. M. Aguado, C. Lumbreras et al., "Incidence, clinical characteristics and risk factors of late infection in solid organ transplant recipients: data from the RESITRA Study Group," The American Journal of Transplantation, vol. 7, no. 4, pp. 964-971, 2007.

[129] S. K. Arthurs, A. J. Eid, P. J. Deziel et al., "The impact of invasive fungal diseases on survival after lung transplantation," Clinical Transplantation, vol. 24, no. 3, pp. 341-348, 2010.

[130] F. Pereyra and R. H. Rubin, "Prevention and treatment of cytomegalovirus infection in solid organ transplant recipients," Current Opinion in Infectious Diseases, vol. 17, no. 4, pp. 357-361, 2004.

[131] L. D. Snyder, C. A. Finlen-Copeland, W. J. Turbyfill, D. Howell, D. A. Willner, and S. M. Palmer, "Cytomegalovirus pneumonitis is a risk for bronchiolitis obliterans syndrome in lung transplantation," The American Journal of Respiratory and Critical Care Medicine, vol. 181, no. 12, pp. 1391-1396, 2010.

[132] R. R. Razonable and A. P. Limaye, "Cytomegalovirus infection after solid organ transplantation," in Transplant Infection, R. A. Bowden, P. Ljungman, and D. R. Snydman, Eds., p. 328, Lippincott Williams and Wilkins, Philadelphia, Pa, USA, 2010.

[133] C. N. Kotton, D. Kumar, A. M. Caliendo et al., "International consensus guidelines on the management of cytomegalovirus in solid organ transplantation," Transplantation, vol. 89, no. 7, pp. 779-795, 2010.

[134] N. Singh and D. L. Paterson, "Aspergillus infections in transplant recipients," Clinical Microbiology Reviews, vol. 18, no. 1, pp. 44-69, 2005.

[135] C. Pinet, W. Palka, D. Metras, P. Thomas, B. Méric, and J.-F. Dumon, "Management of an intrabronchial rupture of right main pulmonary artery: a case report," Chest, vol. 121, no. 3, pp. 988-990, 2002.

[136] A. Solé and M. Salavert, "Fungal infections after lung transplantation," Current Opinion in Pulmonary Medicine, vol. 15, no. 3, pp. 243-253, 2009.

[137] D. C. Chambers and A. Solé, "Mold infections in cardiothoracic transplantation," in Diagnosis and Management of Infectious Diseases in Cardiothoracic Transplantation and Mechanical
Circulatory Support, M. L. Mooney, M. M. Hannan, S. Husain, and J. K. Kirklin, Eds., pp. 195-209, International Society of Heart and Lung Transplantation, Addison, Tex, USA, 2012.

[138] S. Koo, D. W. Kubiak, N. C. Issa et al., "A targeted peritransplant antifungal strategy for the prevention of invasive fungal disease after lung transplantation: a sequential cohort analysis," Transplantation, vol. 94, no. 3, pp. 281-286, 2012.

[139] R. Herbrecht, D. W. Denning, T. F. Patterson et al., "Voriconazole versus amphotericin B for primary therapy of invasive aspergillosis," New England Journal of Medicine, vol. 347, no. 6, pp. 408-415, 2002.

[140] J. G. Castro and M. Morrison-Bryant, "Management of pneumocystis jirovecii pneumonia in HIV infected patients: current options, challenges and future directions," HIV/AIDS, vol. 2, pp. 123-134, 2010.

[141] C. Theunissen, C. Knoop, C. Nonhoff et al., "Clostridium difficile colitis in cystic fibrosis patients with and without lung transplantation," Transplant Infectious Disease, vol. 10, no. 4, pp. 240-244, 2008.

[142] F. Patriarchi, M. Rolla, F. Maccioni et al., "Clostridium difficilerelated pancolitis in lung-transplanted patients with cystic fibrosis," Clinical Transplantation, vol. 25, no. 1, pp. E46-E51, 2011.

[143] J. T. Lee, M. I. Hertz, J. M. Dunitz et al., “The rise of Clostridium difficile infection in lung transplant recipients in the modern era," Clinical Transplantation, vol. 27, no. 2, pp. 303-310, 2013.

[144] E. R. Dubberke and S. D. Burdette, "Clostridium difficile infections in solid organ transplantation," The American Journal of Transplantation, vol. 13, supplement 4, pp. 42-49, 2013.

[145] M. R. Zamora, M. Budev, M. Rolfe et al., "RNA interference therapy in lung transplant patients infected with respiratory syncytial virus," The American Journal of Respiratory and Critical Care Medicine, vol. 183, no. 4, pp. 531-538, 2011.

[146] J. D. Christie, L. B. Edwards, A. Y. Kucheryavaya et al., "The Registry of the International Society for Heart and Lung Transplantation: twenty-seventh official adult lung and heartlung transplant report-2010," The Journal of Heart and Lung Transplantation, vol. 29, no. 10, pp. 1104-1118, 2010.

[147] P. Maisonneuve, S. C. FitzSimmons, J. P. Neglia, P. W. Campbell III, and A. B. Lowenfels, "Cancer risk in nontransplanted and transplanted cystic fibrosis patients: a 10-year study," Journal of the National Cancer Institute, vol. 95, no. 5, pp. 381-387, 2003.

[148] K. C. Meyer, M. L. Francois, H. K. Thomas et al., "Colon cancer in lung transplant recipients with CF: increased risk and results of screening," Journal of Cystic Fibrosis, vol. 10, no. 5, pp. 366369,2011

[149] N. V. Frey and D. E. Tsai, "The management of posttransplant lymphoproliferative disorder," Medical Oncology, vol. 24, no. 2, pp. 125-136, 2007.

[150] R. Trappe, S. Oertel, V. Leblond et al., "Sequential treatment with rituximab followed by CHOP chemotherapy in adult Bcell post-transplant lymphoproliferative disorder (PTLD): the prospective international multicentre phase 2 PTLD-1 trial," The Lancet Oncology, vol. 13, no. 2, pp. 196-206, 2012.

[151] A. D. Peebles, "Physiotherapy," in Practical Guidelines For Cystic Fibrosis Care, C. M. Hill, Ed., Churchill Livingstone, London, UK, 1998.

[152] R. J. Shephard, Aerobic Fitness and Health, Human Kinetics, Champaign, Ill, USA, 1994.

[153] J. Schneiderman-Walker, S. L. Pollock, M. Corey et al., "A randomized controlled trial of a 3-year home exercise program 
in cystic fibrosis," Journal of Pediatrics, vol. 136, no. 3, pp. 304310, 2000.

[154] H. C. Selvadurai, C. J. Blimkie, N. Meyers, C. M. Mellis, P. J. Cooper, and P. P. Van Asperen, "Randomized controlled study of in-hospital exercise training programs in children with cystic fibrosis," Pediatric Pulmonology, vol. 33, no. 3, pp. 194-200, 2002.

[155] H. Hebestreit, S. Kieser, S. Junge et al., "Long-term effects of a partially supervised conditioning programme in cystic fibrosis," European Respiratory Journal, vol. 35, no. 3, pp. 578-583, 2010.

[156] H. G. M. Heijerman, W. Bakker, P. J. Sterk, and J. H. Dijkman, "Oxygen-assisted exercise training in adult cystic fibrosis patients with pulmonary limitation to exercise," International Journal of Rehabilitation Research, vol. 14, no. 2, pp. 101-115, 1991.

[157] K. Meyer, L. Samek, M. Schwaibold et al., "Interval training in patients with severe chronic heart failure: analysis and recommendations for exercise procedures," Medicine and Science in Sports and Exercise, vol. 29, no. 3, pp. 306-312, 1997.

[158] M. A. Puhan, G. Büsching, H. J. Schünemann, E. VanOort, C. Zaugg, and M. Frey, "Interval versus continuous highintensity exercise in chronic obstructive pulmonary disease: a randomized trial," Annals of Internal Medicine, vol. 145, no. 11, pp. 816-825, 2006.

[159] W. Gruber, D. Kiosz, K. Paul, and M. Braumann, "Effects of an interval training on a treadmill in CF-patients awaiting lung transplantation," Pediatric Pulmonology, vol. 36, supplement 25, p. 331, 2003.

[160] P. Aurora, A. Wade, P. Whitmore, and B. Whitehead, "A model for predicting life expectancy of children with cystic fibrosis," European Respiratory Journal, vol. 16, no. 6, pp. 1056-1060, 2000.

[161] T. Radtke, A. Faro, J. Wong, A. Boehler, and C. Benden, "Exercise testing in pediatric lung transplant candidates with cystic fibrosis," Pediatric Transplantation, vol. 15, no. 3, pp. 294299, 2011.

[162] K. G. Tantisira, D. M. Systrom, and L. C. Ginns, "An elevated breathing reserve index at the lactate threshold is a predictor of mortality in patients with cystic fibrosis awaiting lung transplantation," The American Journal of Respiratory and Critical Care Medicine, vol. 165, no. 12, pp. 1629-1633, 2002.

[163] S. Mathur, E. Hornblower, and R. D. Levy, "Exercise training before and after lung transplantation," Physician and Sportsmedicine, vol. 37, no. 3, pp. 78-87, 2009.

[164] D. Langer, D. Troosters, C. Burtin et al., "Effects of exercise training after lung transplantation: preliminary results of a randomized controlled trial," The American Journal of Respiratory and Critical Care Medicine, vol. 181, article A1206, 2010.

[165] A. D. Truong, E. Fan, R. G. Brower, and D. M. Needham, "Bench-to-bedside review: mobilizing patients in the intensive care unit-from pathophysiology to clinical trials," Critical Care, vol. 13, no. 4, p. 216, 2009.

[166] U. Tegtbur, C. Sievers, M. W. Busse et al., "Quality of life and exercise capacity in lung transplant recipients," Pneumologie, vol. 58, no. 2, pp. 72-78, 2004.

[167] G. Maury, D. Langer, G. Verleden et al., "Skeletal muscle force and functional exercise tolerance before and after lung transplantation: a cohort study," The American Journal of Transplantation, vol. 8, no. 6, pp. 1275-1281, 2008.

[168] D. Langer, C. Burtin, L. Schepers et al., "Exercise training after lung transplantation improves participation in daily activity: a randomized controlled trial," The American Journal of Transplantation, vol. 12, no. 6, pp. 1584-1592, 2012.

[169] A. M. Downs, "Physical therapy in lung transplantation," Physical Therapy, vol. 76, no. 6, pp. 626-642, 1996.
[170] A. G. Duarte, L. Terminella, J. T. Smith, A. C. Myers, G. Campbell, and S. Lick, "Restoration of cough reflex in lung transplant recipients," Chest, vol. 134, no. 2, pp. 310-316, 2008.

[171] C. Benden, L. B. Edwards, A. Y. Kucheryavaya et al., “The Registry of the International Society for Heart and Lung Transplantation: fifteenth pediatric lung and heart-lung transplantation report-2012," The Journal of Heart and Lung Transplantation, vol. 31, no. 10, pp. 1087-1095, 2012.

[172] C. Colombo, P. M. Battezzati, A. Crosignani et al., "Liver disease in cystic fibrosis: a prospective study on incidence, risk factors, and outcome," Hepatology, vol. 36, no. 6, pp. 1374-1382, 2002.

[173] A. Lindblad, H. Glaumann, and B. Strandvik, "Natural history of liver disease in cystic fibrosis," Hepatology, vol. 30, no. 5, pp. 1151-1158, 1999.

[174] P. Milkiewicz, G. Skiba, D. Kelly et al., "Transplantation for cystic fibrosis: outcome following early liver transplantation," Journal of Gastroenterology and Hepatology, vol. 17, no. 2, pp. 208-213, 2002.

[175] D. Debray, D. Kelly, R. Houwen, B. Strandvik, and C. Colombo, "Best practice guidance for the diagnosis and management of cystic fibrosis-associated liver disease," Journal of Cystic Fibrosis, vol. 10, no. 2, pp. S29-S36, 2011.

[176] R. De Franchis, "Evolving Consensus in Portal Hypertension Report of the Baveno IV Consensus Workshop on methodology of diagnosis and therapy in portal hypertension," Journal of Hepatology, vol. 43, no. 1, pp. 167-176, 2005.

[177] J. K. Dowman, D. Watson, S. Loganathan et al., "Long-term impact of liver transplantation on respiratory function and nutritional status in children and adults with cystic fibrosis," The American Journal of Transplantation, vol. 12, no. 4, pp. 954-964, 2012.

[178] M. R. Miller, R. J. Sokol, M. R. Narkewicz, and M. K. Sontag, "Pulmonary function in individuals who underwent liver transplantation: from the US cystic fibrosis foundation registry," Liver Transplantation, vol. 18, no. 5, pp. 585-593, 2012.

[179] E. F. Nash, C. Volling, C. A. Gutierrez et al., "Outcomes of patients with cystic fibrosis undergoing lung transplantation with and without cystic fibrosis-associated liver cirrhosis," Clinical Transplantation, vol. 26, no. 1, pp. 34-41, 2012.

[180] V. Corno, M. C. Dezza, A. Lucianetti et al., "Combined double lung-liver transplantation for cystic fibrosis without cardiopulmonary by-pass," The American Journal of Transplantation, vol. 7, no. 10, pp. 2433-2438, 2007.

[181] J. P. A. Couetil, D. P. Houssin, O. Soubrane et al., "Combined lung and liver transplantation in patients with cystic fibrosis: a 4 1/2 -year experience," Journal of Thoracic and Cardiovascular Surgery, vol. 110, no. 5, pp. 1415-1423, 1995.

[182] J. M. Borro, P. Rama, T. Rey, and C. Fernandez-Rivera, "Longterm success of combined kidney-lung transplantation in a patient with cystic fibrosis," Archivos de Bronconeumología, vol. 49, no. 6, pp. 272-274, 2013.

[183] J. A. Fridell, R. Vianna, P. Y. Kwo et al., "Simultaneous liver and pancreas transplantation in patients with cystic fibrosis," Transplantation Proceedings, vol. 37, no. 8, pp. 3567-3569, 2005.

[184] J. A. Fridell, T. C. Wozniak, J. A. Powelson, and J. M. Reynolds, "Simultaneous bilateral lung and pancreas transplantation in recipient with cystic fibrosis," Transplantation Proceedings, vol. 40, no. 2, pp. 494-497, 2008.

[185] B. R. Lu and C. O. Esquivel, "A review of abdominal organ transplantation in cystic fibrosis," Pediatric Transplantation, vol. 14, no. 8, pp. 954-960, 2010. 
[186] J. Shaner, L. A. Coscia, S. Constantinescu et al., "Pregnancy after lung transplant," Progress in Transplantation, vol. 22, no. 2, pp. 134-140, 2012.

[187] L. A. Coscia, S. Constantinescu, M. J. Moritz et al., "Report from the National Transplantation Pregnancy Registry (NTPR): outcomes of pregnancy after transplantation," Clinical Transplants, pp. 65-65, 2009.

[188] V. T. Armenti, "Pregnancy after transplantation: milestones and assessments of risk", The American Journal of Transplantation, vol. 11, no. 11, pp. 2275-2276, 2011.

[189] P. E. Munro, A. E. Holland, M. Bailey, B. M. Button, and G. I. Snell, "Pulmonary rehabilitation following lung transplantation," Transplantation Proceedings, vol. 41, no. 1, pp. 292-295, 2009.

[190] V. David, C. Berville, S. Ravilly, and C. Marchand, "Educational needs for transplanted patients," Journal of Cystic Fibrosis, vol. 11, supplement 1, p. S27, 2012.

[191] A. Moran, C. Brunzell, R. C. Cohen et al., "Clinical care guidelines for cystic fibrosis-related diabetes: a position statement of the American Diabetes Association and a clinical practice guideline of the Cystic Fibrosis Foundation, endorsed by the Pediatric Endocrine Society," Diabetes Care, vol. 33, no. 12, pp. 2697-2708, 2010.

[192] T. O. Hirche, J. Bradley, D. d’Alquen et al., "Travelling with cystic fibrosis: recommendations for patients and care team members," Journal of Cystic Fibrosis, vol. 9, no. 6, pp. 385-399, 2010. 


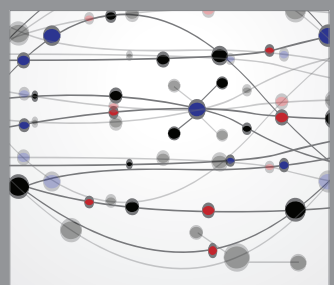

The Scientific World Journal
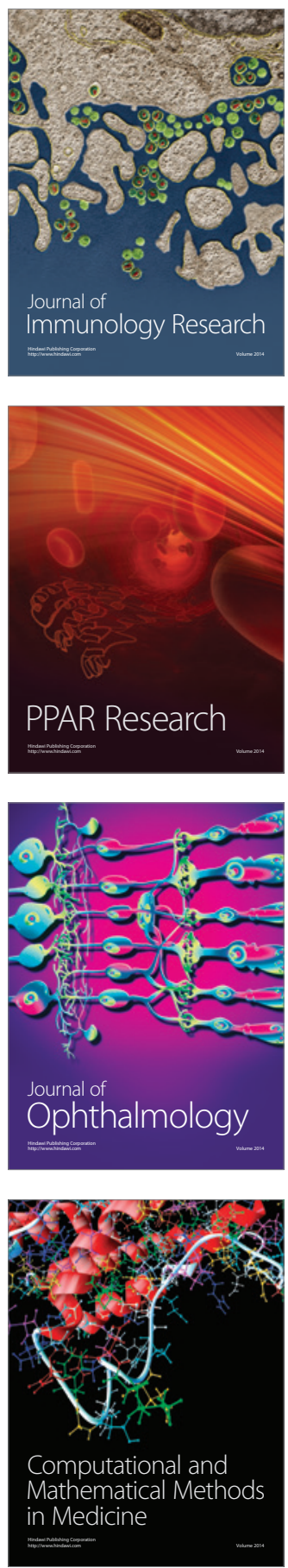

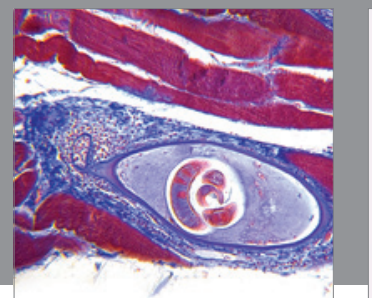

Gastroenterology

Research and Practice
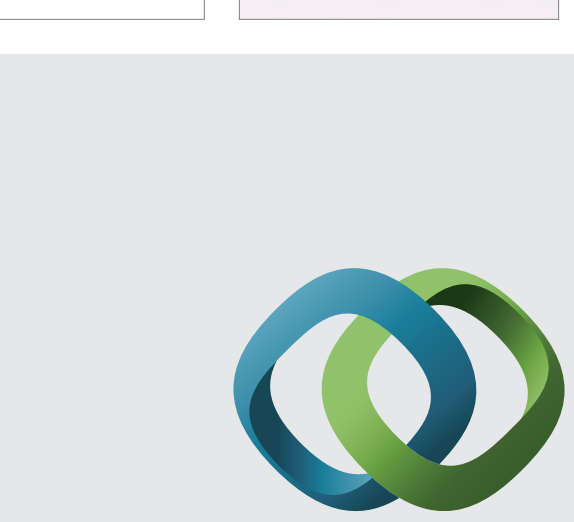

\section{Hindawi}

Submit your manuscripts at

http://www.hindawi.com
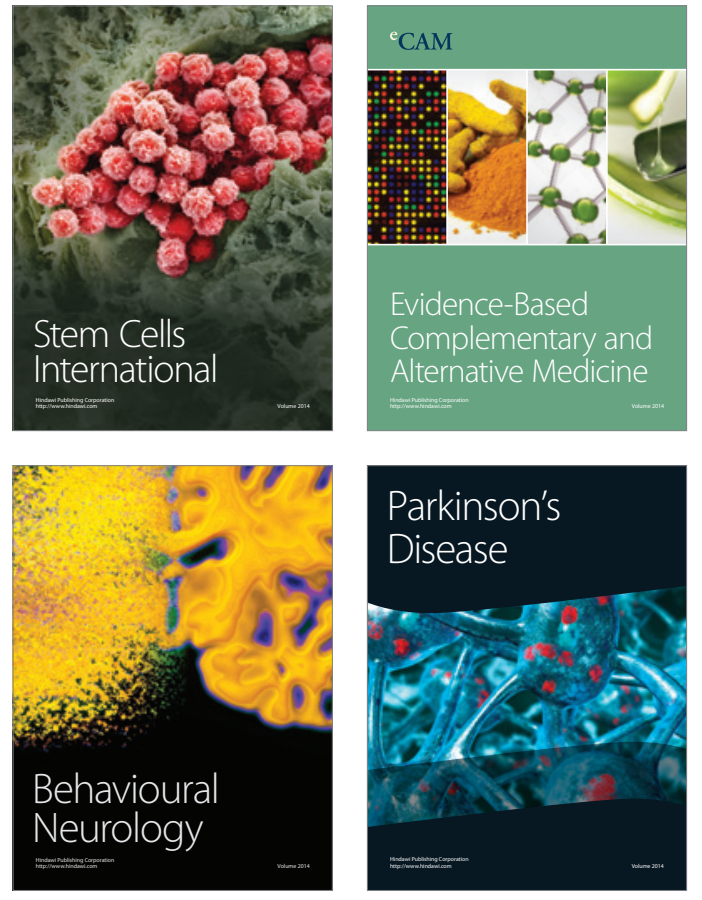
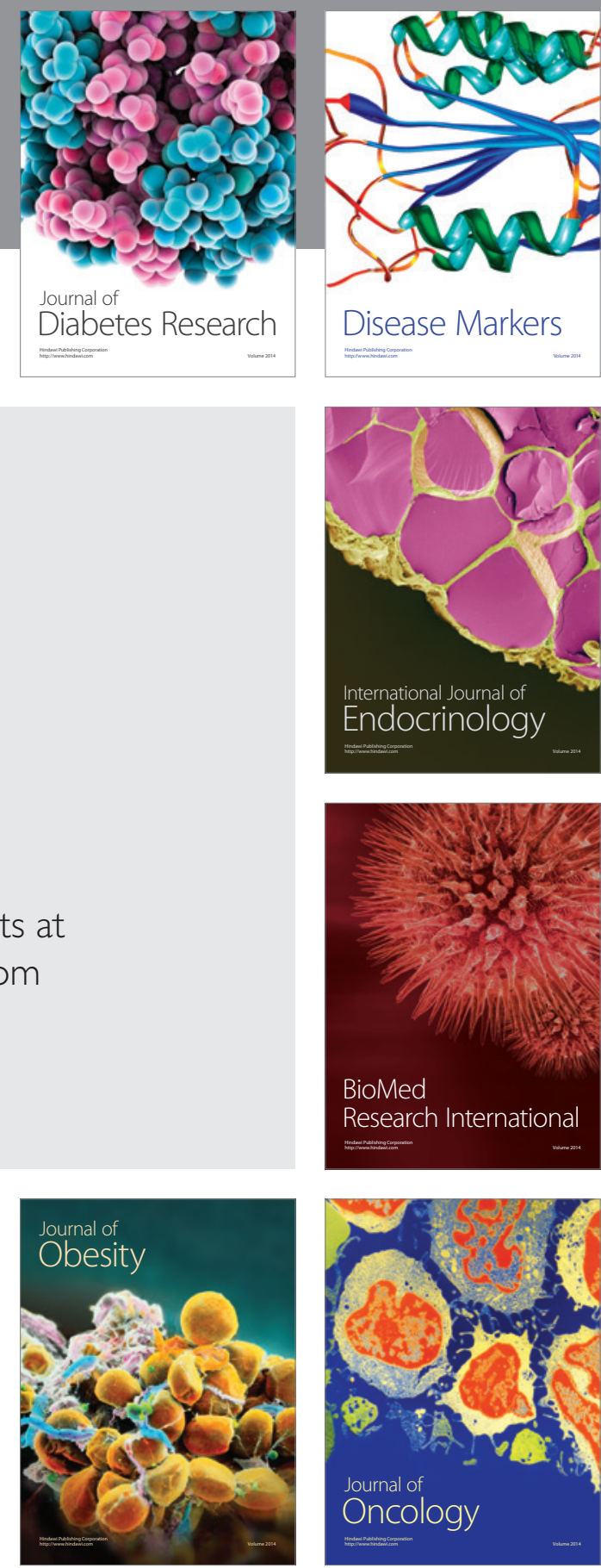

Disease Markers
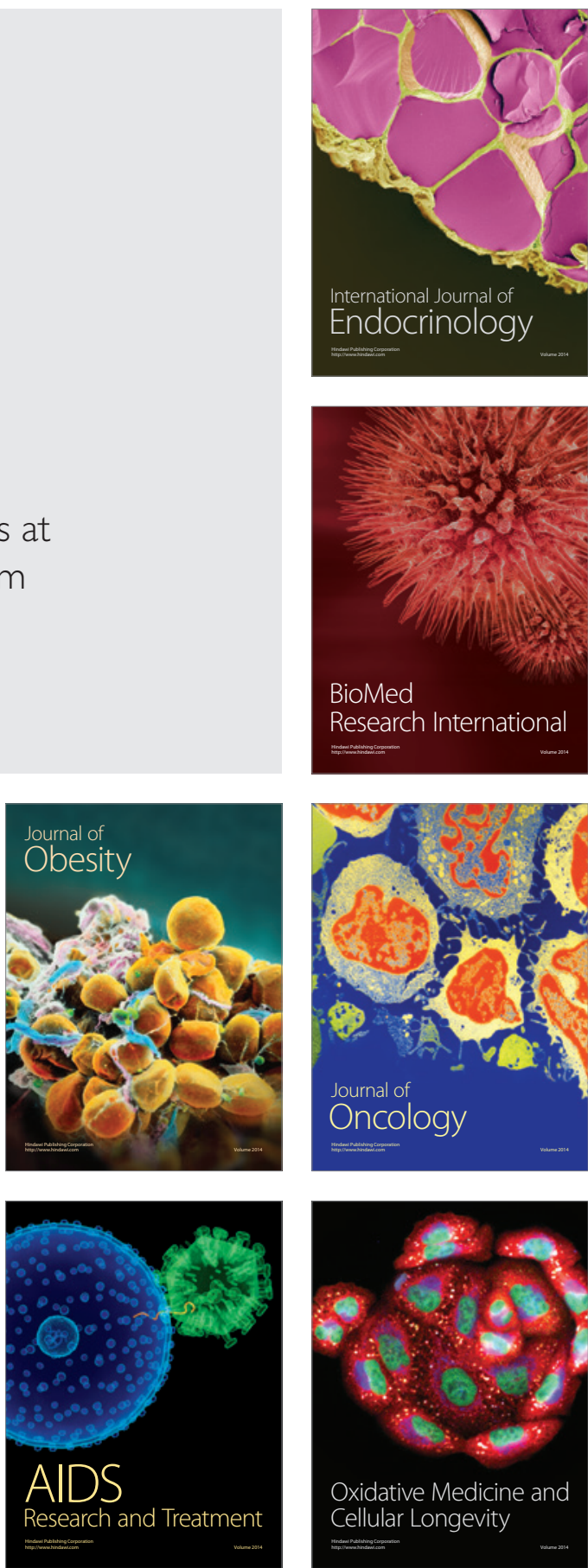